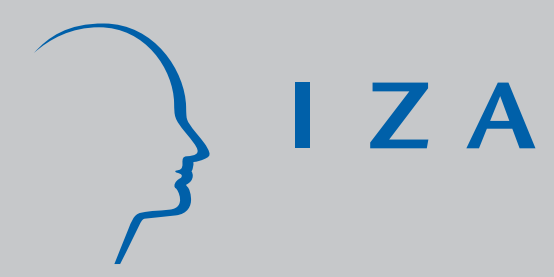

IZADP No. 3502

Labor Market Policies, Institutions and Employment Rates in the EU-27

Riccardo Rovelli

Randolph Bruno

May 2008 


\title{
Labor Market Policies, Institutions and Employment Rates in the EU-27
}

\author{
Riccardo Rovelli \\ University of Bologna, DARRT \\ and IZA \\ Randolph Bruno \\ University of Bologna, DARRT \\ and IZA
}
Discussion Paper No. 3502
May 2008

\author{
IZA \\ P.O. Box 7240 \\ 53072 Bonn \\ Germany \\ Phone: +49-228-3894-0 \\ Fax: +49-228-3894-180 \\ E-mail: iza@iza.org
}

\begin{abstract}
Any opinions expressed here are those of the author(s) and not those of IZA. Research published in this series may include views on policy, but the institute itself takes no institutional policy positions.

The Institute for the Study of Labor (IZA) in Bonn is a local and virtual international research center and a place of communication between science, politics and business. IZA is an independent nonprofit organization supported by Deutsche Post World Net. The center is associated with the University of Bonn and offers a stimulating research environment through its international network, workshops and conferences, data service, project support, research visits and doctoral program. IZA engages in (i) original and internationally competitive research in all fields of labor economics, (ii) development of policy concepts, and (iii) dissemination of research results and concepts to the interested public.
\end{abstract}

IZA Discussion Papers often represent preliminary work and are circulated to encourage discussion. Citation of such a paper should account for its provisional character. A revised version may be available directly from the author. 
IZA Discussion Paper No. 3502

May 2008

\begin{abstract}

\section{Labor Market Policies, Institutions and Employment Rates} in the EU-27*

We compare labor market policies, institutions and outcomes for the EU member states, for the period 2000-2005. We document the main differences in Labor Market Policies across EU members, including new member states after 2004. We focus on indicators of policy generosity (expenditures relative to GDP) and relate these and other policy indicators to indicators of labor market outcomes and performance. Our results show that, on a crosscountry basis, higher rates of employment are in general associated with: (i) higher expenditures on labor market policies, especially on active policies for countries with a high pro-work attitude; (ii) a lower degree of rigidity in labor market institutions and in product market regulation.
\end{abstract}

JEL Classification: J08, J38, J68

Keywords: labor market policies, labor market outcomes, European social models

Corresponding author:

Riccardo Rovelli

Dipartimento di Scienze Economiche

Università di Bologna

Strada Maggiore 45

40125 Bologna

Italy

E-mail: riccardo.rovelli@unibo.it

\footnotetext{
*Substantially revised and rewritten version of "Labor Market Policies and Outcomes: Cross Country Evidence for the EU-27" by Riccardo Rovelli and Randolph Bruno, IZA Discussion Paper No. 3161, November 2007. Section 4 and 5 are entirely new. We wish to thank, without implicating, Giorgio Bellettini, Andrea Ichino, Hartmut Lehmann, Anzelika Zaiceva, and other participants to seminars at the Università di Bologna, Charles University (Prague, CZ) and London School of Economics (UK).
} 


\section{Introduction}

The performance of labor markets is at the center of many analyses and debates on the health of the economies in the European Union. Back in the Eighties, the term "eurosclerosis" was coined, to indicate the combination of slow growth, low employment and rigid labor markets which then characterized many member states of the EU. More recently, the functioning of labor markets is at the center of both the economic and the social pillar of the Lisbon strategy (which the Heads of State or Government of the EU adopted in March 2000) and of its reappraisal in 2005. One main objective of that strategy was to increase job market participation across member states to $70 \%$ by 2010 - a goal that all EU-15 members, but those who had already achieved it in 2000 , are likely to miss.

Not only are labor markets central to economic performance, they also lie at the heart of the social models which so peculiarly characterize many EU members. In a recent Eurobarometer Survey on "European social reality" (2007), a majority ( $51 \%)$ of European Union citizens declared their satisfaction with the quality of the social welfare system in their own country ${ }^{1}$. The report also notes that "over twofifths of European Union citizens feel that their welfare system could serve as a model for other countries (42\%). This belief is most widely held in Finland (79\%) and Denmark (78\%) and least widely so in Portugal (5\%), Latvia (6\%) and Greece (8\%). In Romania and Bulgaria this view is shared by respectively $7 \%$ and $2 \%$ of respondents. People's propensity to feel that their country's social welfare system could serve as a model for other countries is strongly related to whether they feel it provides enough coverage." (id., p.77).

Clearly, social policies matter to the EU citizens. However, shared values and common objectives do not necessarily imply EU competences or EU legislative action. In fact, in most cases subsidiarity implies that competences in the field of social and labor market policies should rest with member states. As the above quote from the Eurobarometer implies, many citizens are indeed happy with the diversity of social policies in Europe - what make some of them unhappy are the shortcomings of their national welfare systems.

1 The specific question asked to the EU-25 citizens was whether their welfare system "provides wide enough coverage" (Eurobarometer Survey, 2007, p.76) 
In this paper we characterize the main cross-country differences in labor market policies across EU member states, and relate various measures and policy indicators to indicators of labor market outcomes and performance. In doing so, we take advantage of recently developed datasets, which include labor market and related indicators and variables, encompassing all or many of the current EU members. Some characteristics of these datasets, especially in the time domain, limit the range of the issues that can be explored. In particular, we shall limit ourselves to an analysis of how employment or unemployment measures are correlated across countries to indicators of labor and product market rigidities, and also to various measures of both active and passive Labor Market Programs (LMP).

The paper is organized as follows. In Section 2 we synthesize the variety of labor market institutions, policies and outcomes within the EU, in reference to all the member states. In Section 3 we present alternative interpretations of the effects of LMP, and propose a framework for the empirical analysis. Results of the econometric analysis are documented in Section 4, while Section 5 presents additional specification and robustness checks. Section 6 concludes. A short Appendix describes the data.

\section{One market for goods, many markets for labor?}

In this section we document the diversity of labor market performance across the member states of the EU. We will also tentatively correlate such diversities with the different labor market models and policies that have been adopted within each EU country, and we shall document to some extent how both policy inputs and economic performances have evolved in recent years.

We extend our comparison, as far as it is feasible, to the whole set of the current EU 27 members. In order to do this in a meaningful way, we focus only on the short period from 2000 to 2005. This choice is motivated by two reasons. First, by the year 2000 the ten transition countries which have now entered into the EU had by most standards completed the period of transitional "confusion". Everywhere post-transition output had completed its U-shaped path; each country had been fully democratic for quite some time; and each was about to qualify as a full market economy. Second, Eurostat has now assembled a rich data set of 
indicators, where all EU-27 members are adequately represented at least since $2000 .^{2}$

Some questions which will be addressed in our analysis are:

- Is it correct to group EU members within four social models, as it had been suggested, among others, by Boeri (2002) and Sapir (2006)?

- Do the groupings within each model stay constant across time?

- Do all the 27 members fit within these models? And where do the New Member States (NMS, who entered the EU after 2004) fit?

- Do countries within each group share similar labor market outcomes? Or how can we instead characterize the diversity of employment outcomes?

To address these questions, in this part of the paper we first describe the "four models" upon which several recent analyses have been bases (section 2.1). In section 2.2 we re-appraise those models in reference to the enlarged (as of 2007) European Union. Labor market outcomes, especially in reference to the so-called tradeoff between equity and efficiency, are examined in section 2.3. Section 2.4 sums up the main evidence on these issues.

\subsection{The Four models}

Box 1 recalls a well-known definition of the four models of social policy prevailing in the $\mathrm{EU}$ at the end of the $20^{\text {th }}$ century.

\section{Box 1}

\section{The Four social policy models according to Boeri (2002)}

Boeri (2002), following Ferrera (1998) suggests that the EU-15 members could be assigned to four different social policy models, covering four different geographical areas:

"The Nordics (Denmark, Finland and Sweden, plus The Netherlands which is a hybrid between the Scandinavian and the Continental models and has recently moved Northwards) [feature] the highest levels of social protection expenditures, and universal welfare provision based on the citizenship principle. Extensive fiscal intervention in labour markets, based on a variety of "active" policy instruments, substantial tax wedges, and relatively extensive employment in the public sector also belongs to this model while unions' presence in the workplace and involvement in the setting and administration of unemployment benefits generates compressed wage structures.

\footnotetext{
${ }^{2}$ Although we have used Eurostat data extensively in our analyses, in many cases we have complemented them with data from other sources. See the Data Appendix.
} 
The Anglo-Saxon countries (Ireland and the UK) ... feature relatively large social assistance of the last resort schemes. Cash transfers are primarily oriented to people in working-age. Activation measures are important as well as schemes conditioning access to benefits to regular employment. On the labour market side, this model is characterized by a mixture of weak unions, comparatively wide and increasing wage dispersion and relatively high incidence of low-pay employment, half-a-way between Europe and the US.

Continental countries (Austria, Belgium, France, Germany, and Luxembourg) ... rely extensively on insurance-based, non-employment benefits and old-age pensions. Large invalidity benefit schemes are also present, which rely on contributions on employment income, along the Bismarckian tradition. While unions' membership rates have been falling quite dramatically in the last 20-25 years (...), a strong unions' influence has been to a large extent preserved by regulations artificially extending the coverage of collective bargaining much beyond unions' presence.

Mediterranean countries (Greece, Italy, Spain and Portugal), [concentrate] their spending on old-age pensions and allowing for a high segmentation of entitlements and status. Their social welfare systems typically draw on employment protection and early retirement provisions to exempt segments of the working age population from participation in the labour market. ... Strong unions' influence has been preserved by practices (e.g., jurisprudence) artificially extending the coverage of collective bargaining. As a result, wage structures are, at least in the formal sector, covered by collective bargaining and strongly compressed in these countries."

Boeri (2002) also observed that: "Three are the main tasks assigned to labour and social policies: i) reduce poverty and, more broadly, income inequalities, ii) protect against uninsurable labour market risk (and its interactions with longevity risk), and iii) increase the rewards from labour market participation." More specifically, in reference to the goals of the Lisbon strategy, he argued that the EU's chances "to become 'the most dynamic economy of the World' will very much depend on its capacity to score better than the US also on the third criterion", that is on increasing the attractiveness of participation.

But why do different countries choose different labor market policies? In his analysis, Boeri observes that "protection against uninsurable labour market risk is typically provided in two ways: (i) by imposing legal restrictions against firing - the so called employment protection legislation (EPL); (ii) by providing unemployment benefits in addition to those established by collective bargaining (UB). The differences between these two systems are clear: EPL protects those who already 
have a job, and does not impose any tax burden; UB can also be targeted to specific groups, but generally provide insurance to the population at large and are typically financed by a tax on those who work. Thus insiders, those with a stable and regular job, typically prefer EPL to UB".

Figure 1 effectively shows how EU countries, toward the end of the 1990s, where characterized by different positions along the EPL-UB tradeoff. In this picture, the four models emerge with sufficient distinction from each other.

[Figure 1 : Boeri 2002]

[Figure 2 : Sapir 2006]

Following along similar lines of reasoning, Sapir (2006) evaluates the performance of the four models according to the third criterion, that is how they may stimulate labor market participation. He observes that the performance of the four models can be usefully compared "with a typology based on two criteria: efficiency and equity. A model will be considered efficient if it provides sufficient incentives to work and, therefore, if it generates relatively high employment rates. It will be deemed equitable if it keeps the risk of poverty relatively low." This comparison is depicted in Figure 2. The four models again appear neatly.

This leaves us with two open questions, which we take up in turn in the following two sub-sections:

(i) Is the diversity of labor market policies today still adequately described by the EPL-UB tradeoff?

(ii) Is there today a systematic link between the adoption of a policy stance in one country and the specific position which it assumes on the equity-efficiency tradeoff?

\subsection{Beyond the four models: a reappraisal for the EU-27}

Does a tradeoff still exist between the amount of (ex ante) protection (measured by the strictness of EPL) and the amount of (ex post) insurance (measured by the payment of UB)? And how does participation to other Labor Market Programmes (LMP) enter into the picture? In this section we shall argue that the EPL-UB tradeoff no longer provides a useful way to summarize the different attitudes of EU members towards labor market policies. Instead, it seems more appropriate to distinguish between countries in terms of the overall policy "generosity". 
Three things have changed, since the beginning of this decade: some countries have had time to improve their old, or to adopt new policies; new members have joined the EU; and we have more and better statistics. ${ }^{3}$ As a starting point to our study, let us look at the data assembled in Table 1.

[Insert Table 1 here]

The first three columns display expenditures in Active LMP as a ratio to GDP for all available EU countries, for the initial and final years of our sample and also the final year (2005) rank. The next three columns display expenditures in Passive LMP (which include UB, redundancy and early retirement), and the following three display Total expenditures. We note that the average expenditure in the EU 15 for active programmes is $0.55 \%$ of GDP, and for passive programmes is 1.41: roughly a 2:5 ratio. In general, however, countries that are generous on one dimension tend to be so also on the other: the rank correlation across countries between expenditures in active and in passive programmes is 0.87 .

- The most "generous" countries include the four Nordic and three Continental countries ( $B E, D E, F R)$. Most of these countries keep the same rank for both active and passive LMP: the two exceptions are SE (2nd in the ranking for active programmes, 10 th for passive) and DE (respectively 7 th and 3rd).

- The least generous includes the three Baltic countries and CZ, GR, RO, SK. Also in these cases each country has similar positions in both rankings.

The last six columns include three different indicators of institutional regulation, and the respective country rankings (Rank $=1$ implies stricter regulation). The indicators are: Rigidity of Employment index (from the WB - Doing Business indicators); Strictness of Employment Protection Law (EPL, from OECD); Product Market Regulation (PMR: regulatory impediments to product market competition, from OECD). If for instance we focus on EPL, the group of the seven "strictest" countries (index 2.5 or above) includes four which are also among the most "generous" (BE, DE, FR, SE). Notice that SE is the only Nordic country in the group. Using the same data, in Figures 3 and 4 we plot the index of EPL strictness against total expenditures on all LMP (as a ratio to GDP), and expenditure on UB per unemployed person (as a ratio to GDP per capita), respectively.

[Figure 3] [Figure 4]

\footnotetext{
${ }^{3}$ See the Data Appendix at the end of the paper.
} 
From both graphs, countries seem to fall essentially in the same three groups. For instance if we rank countries according to the generosity of UB, we find:

- UB less than $25 \%$ of YPC: GR, UK, CZ, HU, PL, SK;

- UB between 30-60\%: all Continental countries; three Mediterranean (IT, ES, PT); two Nordic (FI, SE); IE;

- above 80\%: DK and NL.

On the contrary, the four models suggested by Boeri no longer appear. One reason might be that we have adopted different measures of UB. ${ }^{4}$ In fact, countries may differ from each other not only for the amount they allocate to each type of LMP, but also for the number and type of the intended beneficiaries. A simple way to look at this question is to compare the number of unemployed person to the number of participants to all LMP. As Figure 5 shows, in many countries the latter group is much larger: especially so in $\mathrm{BE}$ and $\mathrm{DE}$, but also in all other Continental and Nordic countries, and in IE and ES.

[Figure 5]

This graph suggests that we should look at how are participants in LMP divided between those who take part in "active" and "passive" measures. This is done in Figure 6, where both variables are measured as \% of the labor force, and each circle is proportional in size to the GDP share of LMP expenditures for that country.

[Figure 6]

Here we see that most countries fall along a 2:1 line, that is, there are approximately two participants to passive policies (mostly UB) for each participant to active policies. Along this line we find both the less and the more generous countries. ${ }^{5,6}$ As this graph makes clear, those countries, which are more generous in terms of participants to LMP, are also often more generous in terms of the share of GDP devoted to such policies, as it is shown in Figure 3 and Table 1.

${ }^{4}$ Figure 1 (Boeri, 2002) displays the percentage of unemployed people reporting benefits, while in Figure 4 we have used UB expenditure per unemployed divided by GDP per capita.

${ }^{5} \mathrm{PL}, \mathrm{SI}$, and GR are not included in the graph, but they would fit in this group too. PT, instead, would appear considerably more generous, and also with a remarkable preference for passive measures.

${ }^{6}$ Only few countries have more participants to active than to passive LMP (that is, they fall below the $1: 1$ line). Of these, ES and SK have the highest rates of participants. 
Summing up, in 2005 and after the new members' accession, the EPL-UB tradeoff does not provide a useful way to summarize the different attitudes of EU members towards labor market policies. Instead, it seems reasonable to distinguish essentially two groups:

- Countries with generous LMP: the four Nordic, plus BE, DE and FR, followed by AT, ES and PT and, in terms of participants involved, especially for UB programmes, also IE. Within this group we find both countries with strict EPL regulations ( $\mathrm{PT}, \mathrm{ES}, \mathrm{FR}, \mathrm{SE}, \mathrm{BE}, \mathrm{DE})$ and others that are very permissive (DK, FI).

- Countries with least generous LMP: first the three Baltics and most other NMS (with PL relatively more generous), followed (in order of increasing generosity) by GR, UK and IT. Also here we find countries with permissive EPL (UK, IE, SK, $\mathrm{HU}, \mathrm{CZ}$ ) and others very strict (GR).

On average, the beneficiaries of UB are double in number than those on other (active) LMP - except in ES, SK, BG, IT, LT, where the ratio of beneficiaries is closer to 1:1. However, if we look at expenditures, the budget for UB in most countries is about half of the overall budget for LMP and sick leave: hence, on average, beneficiaries of UB are treated much more cheaply relative to beneficiaries of other programmes.

\subsection{Equity vs. Efficiency: making room for the new entries}

We now turn to the equity vs. efficiency tradeoff. We update Figure 2, including 25 out of the $27 \mathrm{EU}$ members. ${ }^{7}$ Since in this case we have data over a longer period, we begin to examine the situation in 2000 (Figure 7). Here we observe:

- The "Continental" group has shrunk: only BE and LU are still characterized by low poverty and low employment rate, but have been joined by HU and SI.

- DE and CZ have joined AT and the "Nordic" group (low poverty, high employment rate).

- The "Anglo" group (high poverty, high employment rate) continues to include PT.

\footnotetext{
${ }^{7}$ Note that in passing from Fig. 2 to 7 the vertical scale has been inverted. Also, we shall continue to name the four groups according to the Boeri-Sapir distinction, although clearly they have lost part of their geographical connotation.
} 
- Most new entries are in the "Mediterranean" group (high poverty, low employment rate): BG, EE, LT, LV, MT, PL, RO. Also FR has approached it.

In any case, the graph maintains a heuristic value, as it vividly represents the "Equity vs. Efficiency" choices of different countries, with the Mediterranean model ineffective on both counts.

\section{[Figure 7] [Figure 8]}

However, things move, and sometimes even for the better. The race to abandon the Mediterranean model before it sinks is open, and some do succeed! Figure 8 documents this evolution, between 2000 and 2005. Overall, the EU-15 average has moved towards the Anglo model. More specifically:

- Employment rates have increased, especially for the Mediterraneans, the 3 Baltics, and BG. ${ }^{8}$

- FR is back in the Continental group, being the only country to considerably improve on the Equity dimension.

- PL and RO move in the wrong direction, towards inefficiency and inequity.

Let us now turn to the motivating question: how are outcomes and policies related? We first examine the relation between LMP expenditures (relative to GDP) and poverty risk (Figure 9). Three groups of countries stand out:

- High poverty, low expenditure on LMP: Baltics (3), Mediterraneans (all 4), the IE, UK, PL and RO;

- Low poverty, low expenditure on LMP: most Visegrad (CZ, HU, SK); BG and LU;

- Low poverty, high expenditure on LMP: Continental (4) and Nordic (4).

[Figure 9]

In general, Figure 9 shows a clear negative relation between the ex-post poverty risk and the LMP expenditures, although a few countries enjoy good outcomes without spending. Moreover, in relation to our previous findings, we observe that:

8 The increase in employment rates is not related to cyclical factors. To ascertain this possibility, we recomputed the employment rates, adjusting them for the output gap (Details of the adjustment are available from the authors). The resulting new graph is however not meaningfully different from Figure 8. 
- High poverty countries (after policy transfers) belong in the group which we identified as the least "generous".

- All the more "generous" countries are among those with a low (below 15\%) poverty risk (exception: ES).

In addition, expenditures on LMP are also positively (albeit weakly) associated with employment rates (Figure 10). On the other hand, Figure 11 shows that there is no evident correlation between EPL strictness and employment rates.

[Figure 10] [Figure 11]

\section{$\underline{2.4}$ Summing up:}

A few facts have emerged from our search:

- LMP are quite different across EU members. However, although labor market insiders might still assign a high priority on maintaining strict $E P L$, this kind of protection does no longer seem to be a major discriminating factor between social models. Instead, a simple way to characterize countries is in terms of overall policy generosity. Generous countries (Nordic and Continental countries plus Spain) have broadly similar policies, in terms of both policy coverage (which extends beyond the number of the currently unemployed) and generosity (LMP expenditures relative to GDP). Within this group, some are leaning more towards UB (Germany), others towards active policies (Sweden).

- In terms of outcomes, the equity-efficiency dichotomy noticed by Sapir (2006) still appears. In particular, countries with a high poverty risk generally are also characterized by low employment rates. In this group or close to it we find Greece, Italy and most NMS (with the exception of Czech Republic and Slovenia). All of these are among the less "generous" countries.

- We notice a negative relation between ex post poverty risk and LMP expenditures, which suggests distinguishing 3 groups of countries (see comments to Figure 9, above). In general, more "generous" countries are also more successful at reducing poverty, but Spain and Portugal provide two exceptions.

- With a few exceptions, most countries have either seen an increase of poverty risk or of employment rates, or both, between 2000 and 2005. This would amount to a convergence to the "Anglo" model. But in effect this applies especially to the "Mediterranean" and NMS. On the other hand there is some 
evidence of reduced divergence between the "Nordic" and "Continental" groups (where CZ also belongs). ${ }^{9}$

As a closing note of caution, we should not interpret whatever evidence we have looked at as suggesting that all countries should find and possibly adopt the same, "best" social model. Good social models are expensive (as the Nordic experience proves), but can presumably produce good outcomes if they are coupled with other policies and institutions, which together are conducive to high and increasing levels of employment, productivity and technological progress. Perhaps it is also in some of these characteristics ${ }^{10}$ that lay the secrets of the Nordic success.

\section{Policies, institutions and outcomes: how are they related?}

In the previous section we have observed some graphical relations between labor markets policies and outcomes. The main question emerged so far is whether and under which circumstances policy generosity may be related to more favorable market outcomes. In this section, before moving to a more structured characterization of the data, we propose a synthetic account of the recent literature on these issues. We begin with some quotations that document the extent of recent debates. In general

"there are polar positions on the effectiveness of active labor market programs. On one hand, proponents of these programs argue that active labor market programs are both necessary and useful, short only of a panacea for reducing unemployment and protecting workers. Opponents of the programs tend to summarily dismiss these programs as a waste of public money with high opportunity costs to other social programs and labor market efficiency as a whole." (Dar and Tzanattos, 1999).

1) On the effects of alternative policies, Bassanini and Duval $(2006$, p.6) argue that "changes in policies and institutions appear to explain almost two thirds of noncyclical unemployment changes over the past two decades. ... On average, it is

\footnotetext{
${ }^{9}$ See Zhou (2007) for an analysis of the differences between the Nordic and Anglo groups.

10 These include informal institutions, such as the "civicness" so often referred to in expositions of the Danish welfare system. It also includes policies that lead to deregulation of product markets, high levels of R\&D expenditures, which promote the importance and quality of scientific training and the ability of the financial sector to promote the growth of innovative firms. Some of these aspects are discussed in the EAAG Report (2007), chapter 4.
} 
estimated that a 10 percentage point reduction in the tax wedge, a 10 percentage point reduction of unemployment benefits and/or a decline in product market regulation by two standard deviations would be associated with a drop in the unemployment rate by about 2.8, 1.2 and 0.7 percentage points, respectively".

2) On unemployment benefits, Howell, Baker, Glyn and Schmitt (2007, p.40) suggest that the positive correlation often observed between unemployment and gross benefit replacement ratios should be interpreted as causality running from the former to the latter.

3) On Active Labor Market Programs, Betcherman, Olivas and Dart (2004, p.52) observe that "some ALMPs do have positive impacts, with favorable cost-benefit ratios. However, in many cases, programs have not improved the future employment prospects of participants and, when they have, they have not always done so in a cost-effective manner. ... Employment services are generally the most cost-effective intervention ... and, compared to other ALMPS, ... are inexpensive. Training programs for the unemployed can also have positive impacts on employment ... These programs are most effective when they are workplace-based."

4) On the relation between UB and other LMP, Bassanini and Duval (2006, p.6) observe that "the impact of generous unemployment benefits on unemployment appears to be mitigated by high public spending on ALMPS, perhaps because high spending on ALMPs is often accompanied with strong emphasis on 'activation'".

5) Finally, on EPL, "most of the individual country studies demonstrate that regulations promoting job security ... on net reduce employment" (Heckman and Pagés, 2003, p.6) .

To conclude, we may sum up as follows the main conclusions from the most recent (mostly macro-based) literature on policy effectiveness (under the maintained hypothesis that policies are exogenous to outcomes):

- Active LMP should exert a positive effect on labor market outcomes (employment rates), although the size and cost-effectiveness of such effects may vary according to the type of program and also to cyclical conditions. 
- Passive LMP (especially UB) are expected to have effects of uncertain sign. On the one hand, they might raise the overall participation rate; on the other, they might discourage the search for employment. As we remarked in section 2.2, in our sample "the rank correlation across countries between expenditures in active and in passive programmes is 0.87 ". Hence the remark by Bassanini and Duval (2006) that "the impact of generous unemployment benefits on unemployment appears to be mitigated by high public spending on ALMPs" could be appropriate in our context.

- In general, UB programmes are defined by a large number of parameters that specify entitlements, conditionality, duration, and replacement rates. ${ }^{11}$ Given the aggregate nature of our analysis, we cannot introduce these parameters into the empirical analysis.

- Regulations that either enhance the rigidity of labor markets, or that more generally are likely to shift downwards the firms' demand for labor, are expected to have a negative impact on labor market outcomes.

From a methodological point of view, no matter how confident we might be on the a priori validity of the above considerations, we must be clear that it is not the purpose of this paper to address issues of causality, since we cannot adequately control for the endogeneity of right-hand side variables nor for the exclusion of omitted or confounding factors. In our framework, the above hypotheses may be taken simply as "educated guesses" (as they are sometimes referred to), and our regressions as providing nothing more than a structured description of the data. ${ }^{12}$

Hence, evidence of a positive correlation between policy generosity and employment outcomes will not be interpreted as suggesting that causality runs from the former to the latter. For instance, both variables could be driven by a third, unobserved variable, representing either cultural values or other socioeconomic characteristics of the countries in our sample. Nevertheless, evidence of such a positive correlation could be interpreted as prima facie evidence against the hypotheses of negative causation, and possibly encourage further research.

${ }^{11}$ See on this Nickell, Nunziata and Ochel (2005), who formulate two indicators to account for the difference, respectively, in the replacement rates and duration of unemployment benefits across a number of OECD countries.

12 As a further note of caution, we observe that, although the literature has often considered the interaction between policies, institutions and cyclical conditions, in our framework we are unable to give any role to the latter. 
With this proviso, we introduce in Box 2 the basic structure, which will be used to characterize the data.

\section{Box 2}

\section{The basic model to compare Labor Market Policies across countries}

The general specification of the model is:

$$
\text { Outcome }_{i, t}=\alpha_{0}+\alpha_{1} I N S T_{i, t}+\alpha_{2} \sum_{k}^{K} L M P_{k, i, t}+I_{t}+I_{G}+\varepsilon_{i, t}
$$

where:

Subscript $\quad \mathbf{i}=1, \ldots, 27$ (the EU Member States).

Subscript $\quad \mathbf{t}=$ time.

Outcome: Employment rate (Employed persons aged 15-64 as a share of the total population of the same age group).

INST $_{\mathbf{i}, \mathbf{t}} \quad$ Indicators of institutional or policy characteristics.

$\mathbf{L M P}_{\mathbf{k}, \mathbf{i}, \mathbf{t}} \quad$ Measures of LMP, alternatively defined to include different types of expenditures on active or passive policies.

$\mathbf{I}_{\mathbf{t}}, \mathbf{I}_{\mathbf{G}} \quad$ Time and Geographical Dummies.

\section{Policies and outcomes: cross-country evidence}

In this section we examine the results of estimating alternative specifications of the basic model. The main constraints on our empirical analysis are placed by the extreme shortness of the time-dimension. These constraints are addressed in section 4.1. In section 4.2 we analyze some alternative characterizations of the data.

\section{$\underline{4.1 \text { Data and alternative variables }}$}

Our analysis is based on the estimation of the basic model described in Box 2, where alternative proxies for "Institution" and "LMP" are used. As explained in the next sections, we also allow for some interaction terms. One of our aims is to take into account all the EU member states. In fact, the data available at Eurostat make 
such a comparative analysis now feasible for the first time, at least in certain dimensions, but only for the more recent years. ${ }^{13}$

On the other hand, the New Member States (NMS) which acceded the EU in 2004 and 2007 were also (with the exclusion of Cyprus and Malta) transition countries. Hence, the evolution of their labor markets throughout the nineties is largely idiosyncratic relative to the older EU members, and thus unlikely to be captured by the same econometric model, even in the few cases for which we have data. In this respect, the constraint that most data are available only since 2000 is germane to the desire to adopt the same modeling framework for all the EU-27 Members.

In addition, although for most countries we have annual data for both labor market outcomes and policies for the period 2000-2005, there is very little time-variability for each country, especially for the policy variables, and even less so for measures of institutional quality. ${ }^{14}$ Thus, even within the short sample of six years for which data are available, there is little hope to conduct a meaningful panel analysis: in this case, country fixed effects are likely to pick up most of the variability in the data.

[Insert Table 2 here]

These characteristics of the data set suggest that we should model the data essentially in the cross-country dimension. Thus below we report on regressions with 2-period pooled data, where each period is defined as the average of yearly data (2000-02 and 2003-05).

\subsection{Alternative characterizations of the data}

In this section we explore in a multivariate context the relation between employment levels (on the left hand side) and different country-based measures of

13 Our full sample will span from the year 2000 onward. Longer time series are available, for the dependent and independent variables, only for a subset of the EU members.

${ }^{14}$ See Table 1 for data on labor market institutions and labor market policies, and Table 2 on labor market outcomes. Note that often institutional variables are measured at frequencies longer than a year. 
policies, institutions and culture. All the regressions examined below are estimated with robust standard errors ${ }^{15}$ using 2-period pooled data (as defined above). ${ }^{16}$

[Insert Table 3 here]

Table 3 displays a first set of regressions with alternative combinations of right hand-side variables. Below we comment on each regression in turn.

Equation 1: old geography. We first regress employment rates on geographical groupings of countries, defined as in Boeri (2002) and Sapir (2005), adding only one dummy for the New Member States (NMS). Actual and fitted data are plotted in Figure 12. The large horizontal overlap of the different groups shows that this in not a good way to characterize the data.

\section{[Insert Figure 12 here]}

Equation 2: new geography. As a first alternative, we use different geographical dummies: we include Cyprus and Malta in the Mediterranean group; Czech Republic, Hungary and Slovakia in the Continental; and we split the other NMS between a group with fast growing employment rates (FTR: Estonia, Latvia, Lithuania, Slovenia, Bulgaria) and one of slow growing (PoRo: Poland, Romania). Although this modelization fits the data marginally better, there is still considerable horizontal overlap between the different groupings.

Equation 3. GDP per capita may be the single variable that best ranks countries in terms of their overall productive efficiency and welfare level. Using lagged GDP-pc as the only regressor, however, equation provides a poor characterization of the data. Nevertheless we shall retain this as a control variable in most subsequent regressions.

Equations 4-5: Labor market policies and GDP-PC. In eq. 4, we introduce a measure of policy generosity (the ratio of expenditures on ALMP to GDP) and an index of policy-induced rigidities (Index of Employment Rigidity ${ }^{17}$ ). Although the coefficients of the two right-hand variables are strongly significant, the overall fit is rather poor. The inclusion of lagged GDP-pc (eq. 5) changes the point coefficient and reduces the significance of the ALMP measure; on the other hand, the overall

\footnotetext{
${ }^{15}$ Residuals are clustered at the level of the country. Note that point estimates are identical to those obtained with OLS, whereas (in case of correlated residual for the same country) standard errors are larger than with OLS.

${ }^{16}$ Each regression includes a maximum of 15 observations for 2000-02 and 23 for 2003-05.

17 This is obtained from the "Doing Business Database" of the World Bank.
} 
fit improves only marginally, and is considerably lower than in the "pure geography" model.

Equation 6: Labor market policies and geography. Eq. 6 includes all variables mentioned so far: the overall fit is quite high, but no regressor is individually significant. ${ }^{18}$ Visually, however, actual and fitted data begin to take position along a 45 degree line (Figure 13).

\section{[Insert Figure 13 here]}

\section{Equation 7 -10: Accounting for cultural differences}

In eqs. 7 and 8 we add, to the set of right-hand variables already included in eq. 6, a new variable, equal to 1 for all countries with prevailing Catholic or Orthodox religion. This dummy is interacted with the variable measuring the generosity of ALMP. The motivation is that the inducement to actively search for a working position may become more effective when family networks are less prominent, and where social pressures towards self-responsibility are stronger. We assume these pressures to be stronger in countries where the majority of the population is not affiliated to the Catholic or Orthodox churches. ${ }^{19}$ In fact, the overall fit of this equation is quite high (see Figure 14, which plots eq.7). The interaction variable between the religion dummy and the ALMP measure is the only significant regressor (in addition to geography dummies) and points to a negative correlation between employment rates and policy measures, but only in countries with prevailing Catholic or Orthodox affiliation.

\section{[Insert Figure 14 here]}

To explore another dimension of the relation between cultural variables and labor markets, in eqs. 9 and 10 we introduce a measure of attitudes towards work. We consider the response to the question whether "people should not have to work if they don't want to", which is being asked in the World Value Surveys. We normalized answers in the range between strongly disagree-strongly agree in the numerical range 0-1: a value of zero (strong disagreement with the above

${ }^{18}$ We attribute this result to the high correlation between GDP per capita and Geographical Dummies.

${ }^{19}$ Countries where the majority of the population is neither Catholic nor Orthodox have a Protestant or Lutheran majority. The only exception is the Czech Republic, where $59 \%$ of the population is unaffiliated. 
statement) suggests a "pro-work" attitude, whereas a value of 1 implies more tolerance towards shirking. We introduce the new variable, "attitude towards work", both by itself and interacted with the ALMP measure. Taking into account both regressors, we observe that in countries where the expenditure on ALMP policies is less than $1 \%$ of $\mathrm{GDP}^{20}$ the coefficients on the new variable point to a negative partial correlation between pro-work attitudes and employment rates (see also Figure 15).

\section{[Insert Figure 15 here]}

Summing up, we may now synthesize some results of the alternative characterizations of the data, which are assembled in Table 3. First, we may notice that equations 6 to 10 provide a substantially good fit. But do these different specifications allow us to single out a "robust" partial correlation coefficient between the adoption of ALMP and employment outcomes? In two cases a strong positive and significant coefficient is estimated (eqs. 4 and 10), and in several cases we observe a significant interrelation effect between policy and culture (eqs. 7 to 10). The point estimates of the coefficients, however, vary considerably with changes in the specification. This suggests that several variables should ideally be included in an all-encompassing model of employment rates, and until this can be done (which would require the availability of more observations, especially in the time dimension) judgment must be suspended both on the numerical value of the estimated partial correlations and especially on a more structural or "causal" interpretation of the relation between policies and outcomes.

\section{Further specification searches}

In this section we follow up on the previous remarks and report on additional specification searches, in order to explore the possible role of outliers and to compare the different significance and interpretation of various institutional and policy variables.

\subsection{The role of potential outliers}

As a first check of the reliability of our results, we have explored whether they might have been affected by the inclusion of a few "extremely divergent" countries. Thus we have re-estimated the best-fitting equations from Table 3 (eqs. 8 and 10)

${ }^{20}$ That is, in all countries except for Denmark and Sweden. 
by alternatively excluding each one of the countries in the initial sample. Results are almost identical to those on the whole sample. ${ }^{21}$

\section{$\underline{5.2}$ Other institutional variables}

In the empirical literature, a battery of institutional variables possibly correlated with labor market outcomes have been used to model the employment or unemployment rate. In addition to the rigidity of employment measure which we have used so far, other variables which have been used in other works include indicators of the employment protection legislation (EPL), product market regulation (PMR) and the tax wedge (TW).

\section{[Insert Table 4 here]}

In Table 4 we include several equations where Rigidity (the WB-Doing Business indicators of Employment Rigidity) has been replaced either with EPL (the OECD index of the strength of the Employment Protection Legislation) or with PMR (the OECD index of impediments to Product Market competition). Surprisingly (from the view point of a "causal" interpretation) the partial correlation between EPL and employment rates is either not significant or weakly positive (see eqs. $1,2,3$ ). This is contrary to the results reported by Bassanini and Duval (2006). ${ }^{22}$ However, we must notice that the introduction of EPL has the main effect of reinforcing the positive sign of the ALMP measure (see eq.3 especially), and in addition there is also some evidence (from eq. 1bis) that EPL might be related to the employment rate non-monotonically. In particular, when their interaction term is introduced, a positive correlation between EPL and employment rates appears only for low levels of ALMP ( $<1 \%)$, while it is negative for higher values ( $>\% 1)$.

The last three eqs. in table 4 give instead evidence of a negative partial correlation between employment rates and PMR. This link is especially strong and significant in eq. 6, where also the "attitude to work" variable has been introduced.

Finally, measures of the tax wedge are never significant, and we do not report the results of these regressions.

\section{$\underline{5.3}$ Potential confounders}

\footnotetext{
${ }^{21}$ Results available on request.

22 EPL is available for 1998 and 2003 only, and - unlike Rigidity - it is available only for 18 EU member countries.
} 
In order to take into account potential confounding variables which might have been excluded from the previous regressions, we have alternatively introduced, in the same format adopted for Table 4, measures of net inflows from migration into the labor force and measures of income inequality. Neither variable is significant in the regressions for the employment rate, and we do not report these results.

\section{$\underline{5.4 \text { Alternative measures of Active LMP }}$}

In all the regressions examined so far, LMP have been measured as the ratio of total expenditure on ALMP to GDP. We have also experimented with two alternative measures: the total number of participants to each policy programme and the expenditure per participant as a ratio of each country's GDP per capita. Substituting these measures in the same regressions as reported in Table 3, they were never significant. ${ }^{23}$ This is in contrast to what is reported by Bassanini and Duval (2006), who instead measure LMP as the GDP ratio of expenditures per participant to each policy program.

\subsection{Alternative measures of labor and social policies}

Until so far we have concentrated on the role of ALMP. In Table 5 we have reproduced selected equations from Table 3 and 4, replacing our measure of ALMP with a similarly constructed measure of Total (Active and Passive) LMP. In Table 6, we have instead used only measures of Passive LMP. Finally, in Tables 7 and $\underline{8}$ we have used two policy measures computed on OECD data: total ALMP and also a wider measure of labor market-related policies. ${ }^{24}$

$$
\text { [Insert Tables 5-6- } 7 \text { - } 8 \text { here] }
$$

For each new table, the changing patterns of significance and the point values of individual coefficients follow closely enough those of the equivalent regressions from Tables 3 and $4 .{ }^{25}$

23 Results not reported in the paper, available on request.

24 Labor market-related expenditures include expenditures on all active and passive policies, as classified by the Oecd, and also family and housing expenditures. The Oecd classification is similar to, but not identical with that of Eurostat. Also, Oecd data are available only for a subset of all EU-27 members. In all cases we normalize variables as a ratio of each country's GDP.

${ }^{25}$ In order to have a comparable number of observations with the regressions reported in the previous tables, we had to extend our sample to begin in 1998. Results are not affected by these changes in the dimension of the sample. 


\section{Conclusions}

In this paper we document the difference between labor market policies across EU members, and we propose a simple, although clearly not exhaustive way to characterize this difference in terms of policy generosity (the size of LMP expenditures relative to GDP). In this respect, visual inspection of the data suggests that higher rates of employment are associated with higher expenditures on labor market policies. However, we refrain from interpreting this correlation in terms of causality, since any correlation between policies and economic outcomes could also be driven by unobserved variables, such as cultural values or other socio-economic characteristics of the countries included in our sample.

However we suggest that evidence of a positive correlation between policy generosity and employment outcomes could be interpreted as prima facie evidence against the hypothesis of negative causation from the former to the latter. Despite some variability in the point estimates, this positive correlation emerges consistently across different specifications and controlling for other, potentially confounding factors. It applies to both active and passive labor market policies. The point estimates of these effects are however not generally robust to changes in the specification.

The role of other institutional variables, related to the regulatory regimes in either the labor or product markets, is also explored. In one case, using PMR, a measure of regulatory impediments to product market competition, we find evidence of a consistently negative correlation between regulations and employment rates. Other institutional variables, such as measures of the strictness of Employment Protection Legislation (EPL) and of Rigidity of Employment conditions (Rigidity), have a more ambiguous and in general non monotonous relation with labor market outcomes: namely, the correlation between EPL and employment rates becomes negative for countries with more generous LMP. In reference to PMR, we tentatively suggest that its relevance may be due to the fact that, while labor and product market regulations and rigidities are often correlated across countries, PMR might have an additional, negative effect on the total factor productivity of the regulated firms. In particular, PMR may also direct firms' investments away from innovative sectors, where employment growth is more likely to be located. ${ }^{26}$ Thus

\footnotetext{
${ }^{26}$ See Nicoletti and Scarpetta (2005).
} 
the way in which the two sets of regulations interact is possibly complex, and needs to be understood in more detail, and in a broader framework.

We have also tentatively explored the role of cultural variables, which might be related to the effectiveness of labor market policies. We found some preliminary evidence in this respect for variables reflecting either the prevailing religion or the attitudes towards work reported in each country.

In conclusion, the main advantage of the format of analysis adopted in this paper is that, for the first time, it allows to document and systematically compare labor market outcomes and policies in both old and new EU member states. On the other hand, the aggregate nature of the data, and the fact that they are available only for the most recent years, entails several limitations, which will have to be overcome by future work. In particular it would be important to employ indicators of labor market programs that take into account not only the sheer dimension but also the different design, induced incentives and hence also efficiency of the policies adopted in each country. A prerequisite for such analysis is of course the availability of more observations in the time dimension, in order to overcome the essentially cross-sectional character of our analysis. 


\section{References}

Bassanini, Andrea; and Duval, Romain (2006) "Employment Patterns in OECD Countries: Reassessing the Role of Policies and Institutions". OECD Economics Department W.P. 486.

Betcherman, Gordon; Olivas, Karina; and Dar, Amit (2004) "Impacts of Active Labor Market Programs: New Evidence from Evaluations with Particular Attention to Developing and Transition Countries". World Bank - Social Protection D.P. 04.02

Boeri, Tito (2002) "Let Social Policy Models Compete and Europe Will Win". Unpublished.

Dar, Amit; and Tzannatos, Zafiris (1999) "Active labor market programs: a review of the evidence from evaluations". World Bank - Social Protection D.P. 99.01.

EEAG (European Economic Advisory Group) (2007). Report on the European Economy 2007. Cesifo. http://www.cesifo-group.de

Eurobarometer survey (2007) "European social reality". Special Eurobarometer 273, February. http://ec.europa.eu/public opinion/archives/ebs/ebs 273 en.pdf

Ferrera, Maurizio (1998) "The Four 'Social Europes': Between Universalism and Selectivity". In Rhodes, Martin; and Yves Meny (eds.) The future of European welfare: a new social contract?, Basingstoke: Macmillan.

Heckman, James; and Pages, Carmen (2003) "Law and Employment: Lessons from Latin America and the Caribbean". NBER w.p. 10129.

Howell, David R.; Baker, Dean; Glyn, Andrew; and Schmitt, John (2207) "Are Protective Labor Market Institutions at the Root of Unemployment? A Critical Review of the Evidence". Capitalism and Society, The Berkeley Electronic Press, 2(1), Article 1.

Nicoletti, Giuseppe; and Scarpetta, Stefano (2005) "Regulation and economic performance: product market reforms and productivity in the OECD". OECD Economics Department W.P. 460.

Nickell, Stephen, Nunziata, Luca; and Ochel, Wolfgang (2005), "Unemployment in the OECD since the 1960s: What Do We Know?", The Economic Journal, 115, pp 1-27. 
Sapir, André (2006) "Globalization and the Reform of European Social Models". Journal of Common Market Studies, 44 (2), pp. 369-390.

Zhou, Jianping (2007) "Danish for All? Balancing Flexibility with Security: The Flexicurity Model". IMF Working Paper no. 07/36, February.

\section{Appendix: The Data}

We have assembled a data set for the EU-27 members, based on the following main sources:

* Eurostat (http://epp.eurostat.ec.europa.eu): National Accounts and Public Finance data. Growth rates. Structural indicators on innovation and research, education, employment, unemployment, inequality and social cohesion, market integration and business demography. Expenditure and participants to labor market programmes.

In particular, we have adopted from Eurostat the following classification for Expenditures on LMP:

Active:

1. labour market services

2. training

3. job rotation and job sharing

4. employment incentives

5. integration of the disabled

6. direct job creation

7. start-up incentives.

Passive:

8. out-of-work income maintenance and support

9. early retirement.

* OECD (http://stats.oecd.org/WBOS/Default.aspx): Expenditure on labor market programmes and EPL indicators.

* European Bank for Reconstruction and Development (http://www.ebrd.com/country/sector/econo/stats/index.htm): Transitional indicators on privatisation, restructuring, liberalisation, and other reforms.

* World Bank-Doing Business (http://www.doingbusiness.org/EconomyRankings/) Data on ease of doing business, of employing workers and of paying taxes.

* CIA World Factbook (https://www.cia.gov/library/publications/the-worldfactbook/index.html). Data on religions.

* World Values Survey (http://www.worldvaluessurvey.org/). Data on attitudes toward work.

A complete description of the data set used can be obtained from the authors. 


\section{FIGURES}

Figure 1

The EPL / UB Trade-Off

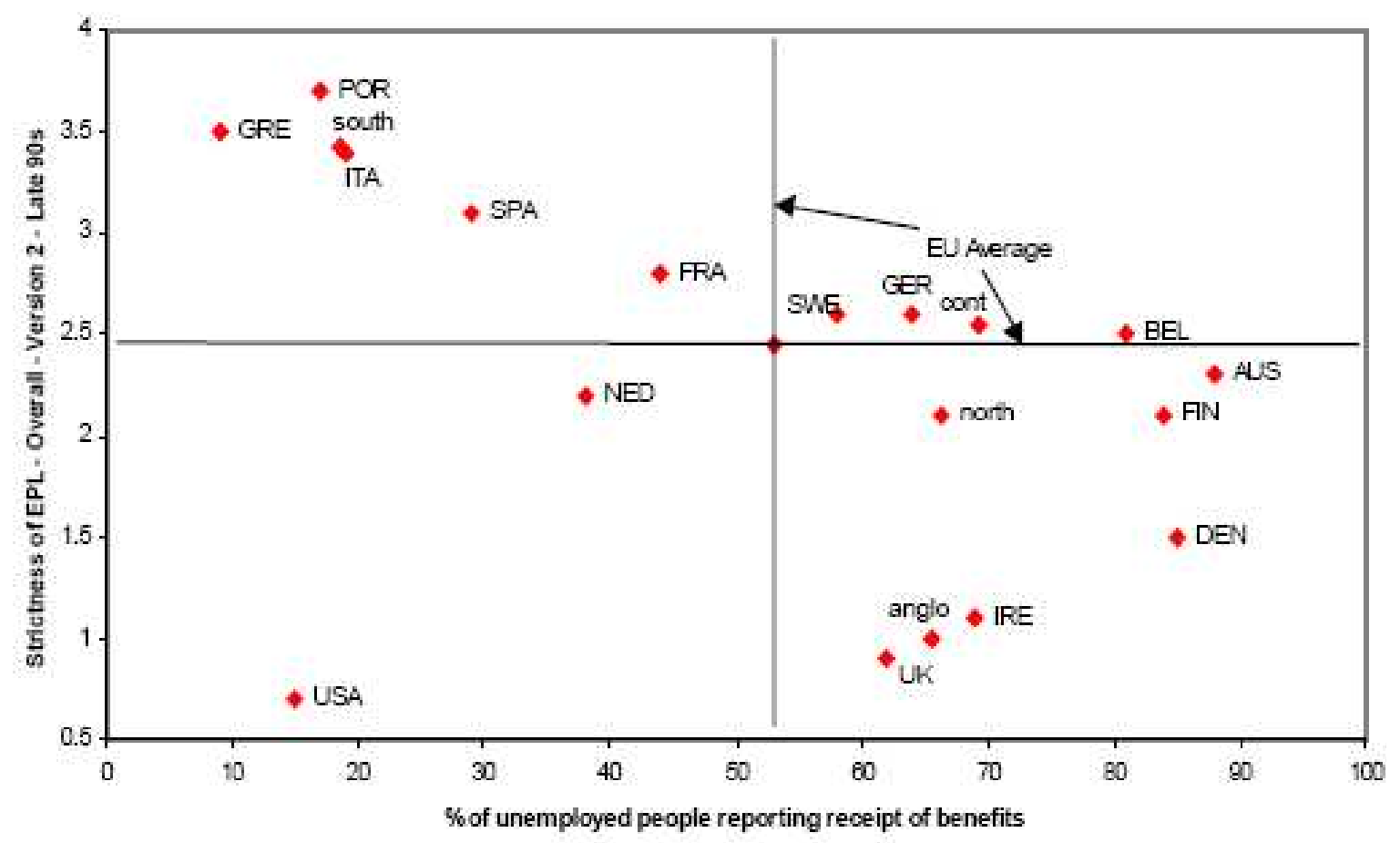

Source: Boeri (2002)

Figure 2

An Equity / Efficiency Trade-Off ?

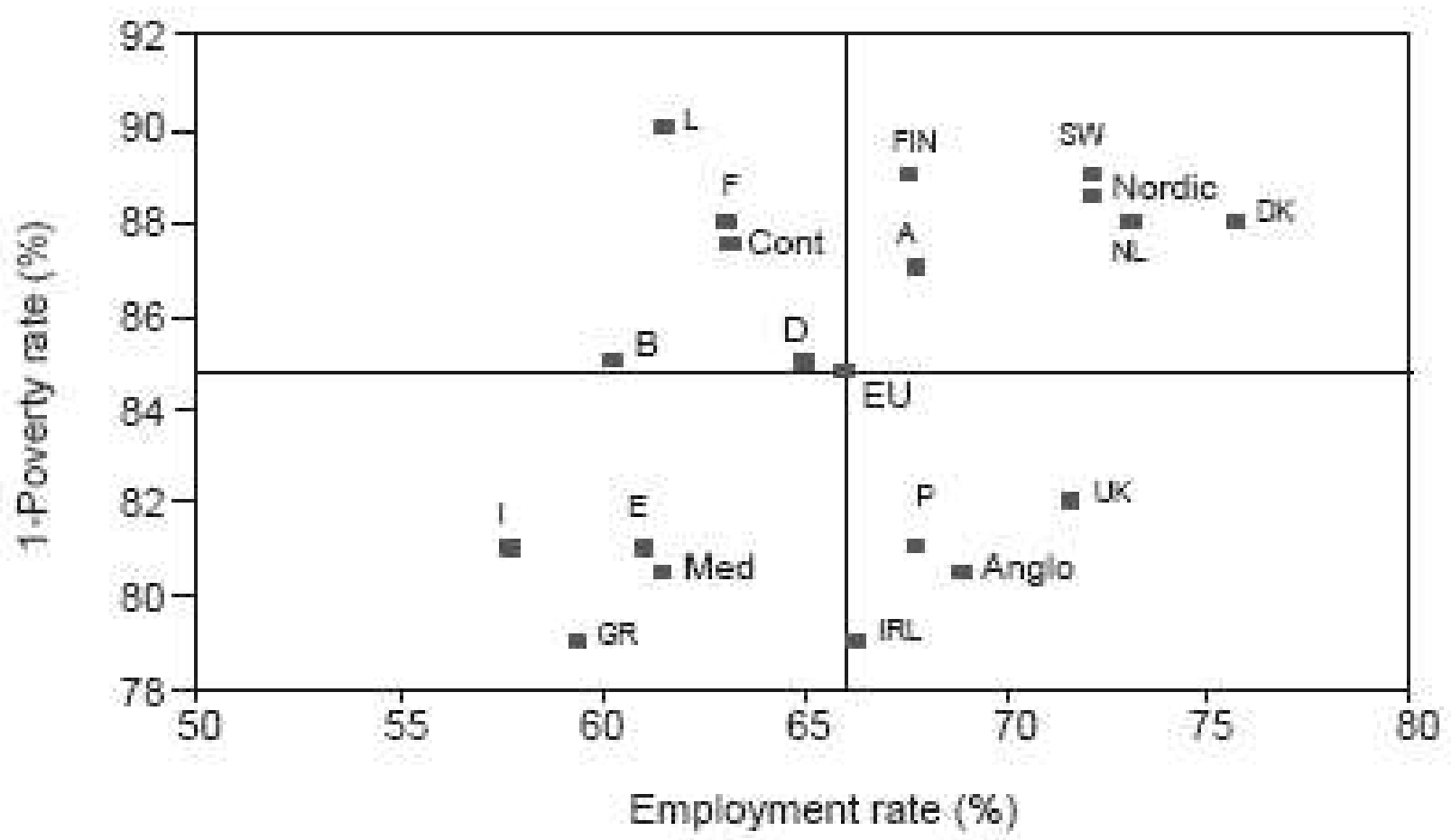

Source: Sapir (2006) 
Figure 3

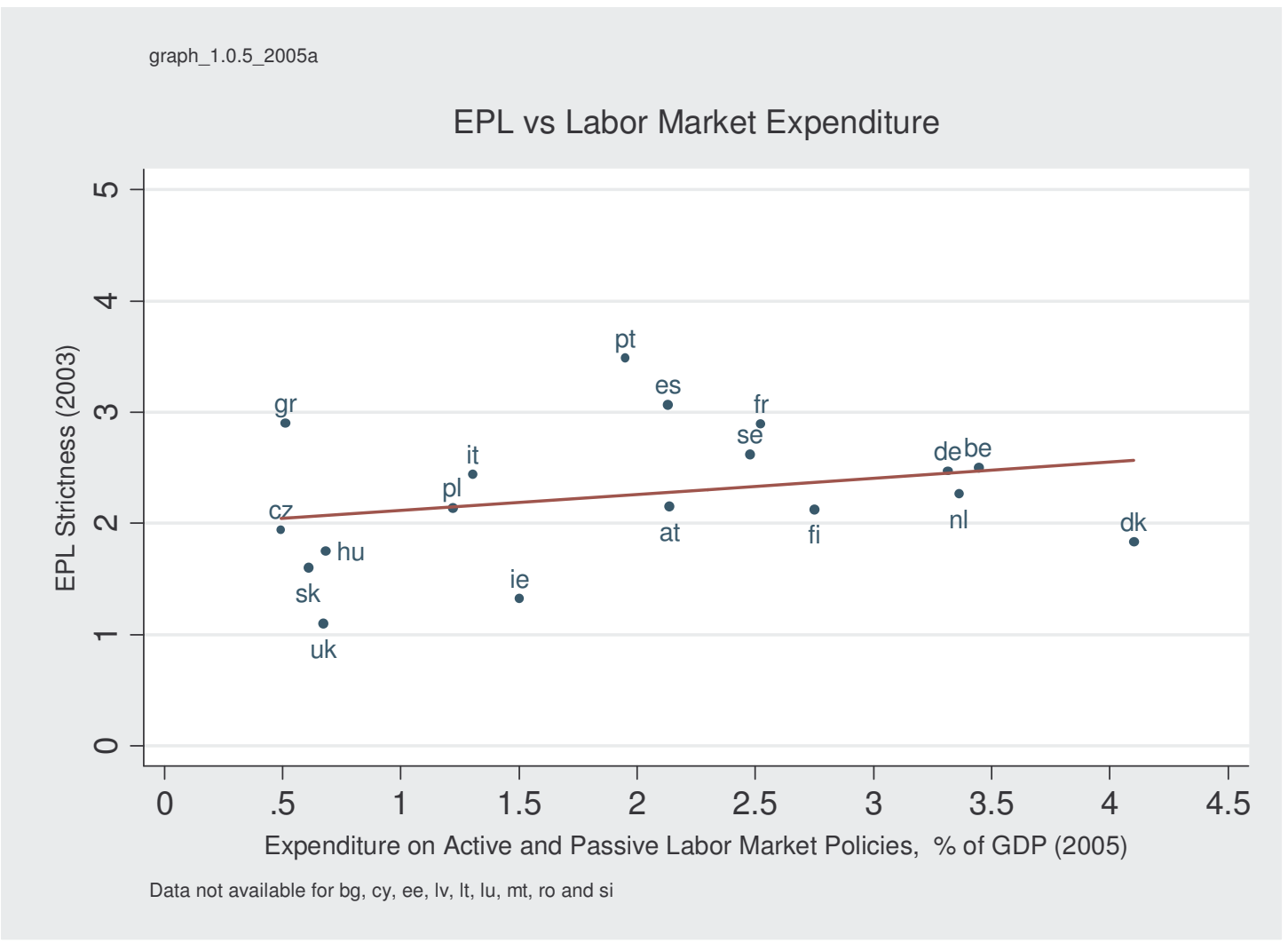

Figure 4

graph_1.0.3_2005b

EPL vs UB expenditure per Unemployed relative to YPC

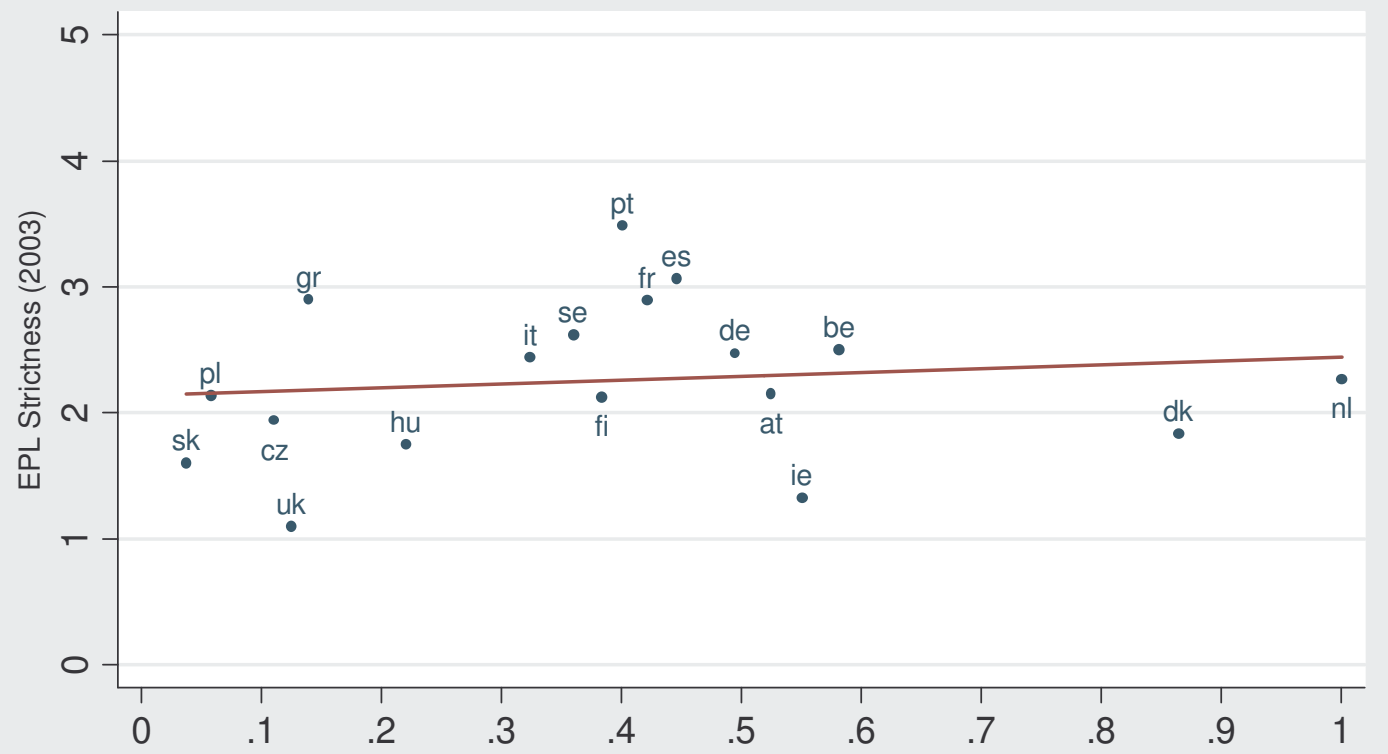

Expenditure on out-of-work income maintenance and support per unemployed relative to YPC (2005) Data not available for bg, cy, ee, Iv, It, lu, mt, ro and si 
Figure 5

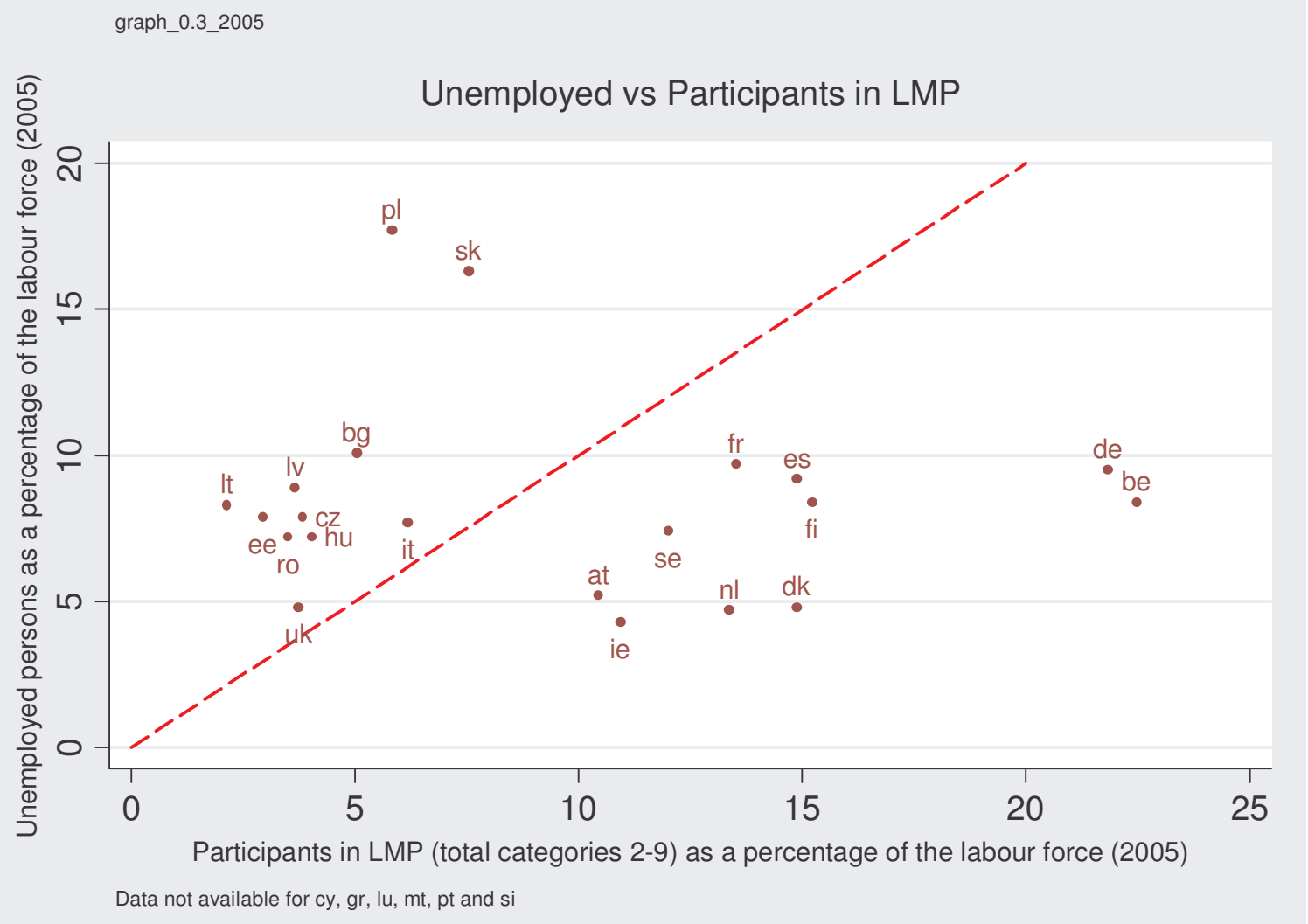

Figure 6

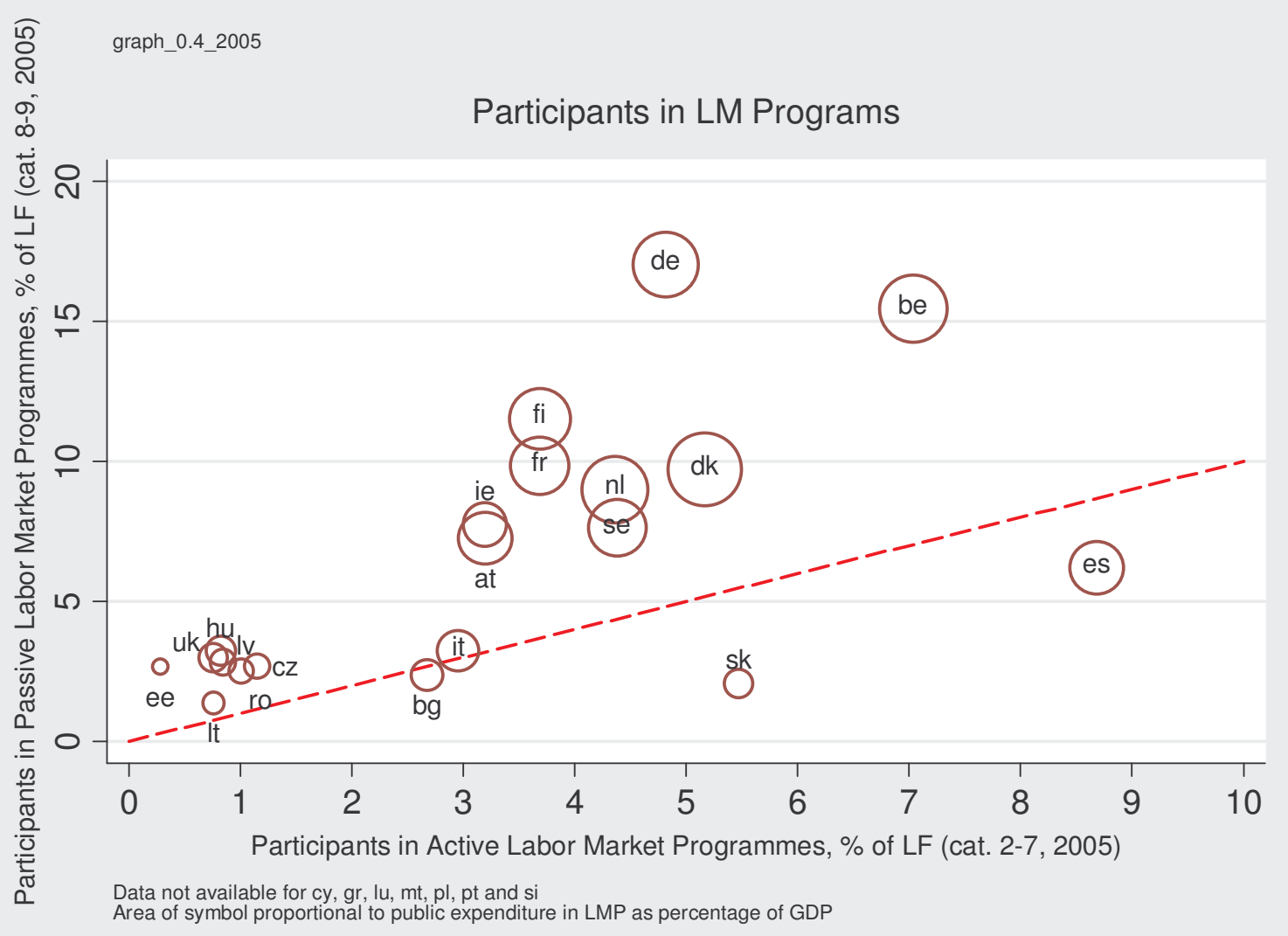


Figure 7

graph_1.1_2000

EU27: Poverty rate vs Employment rate, 2000

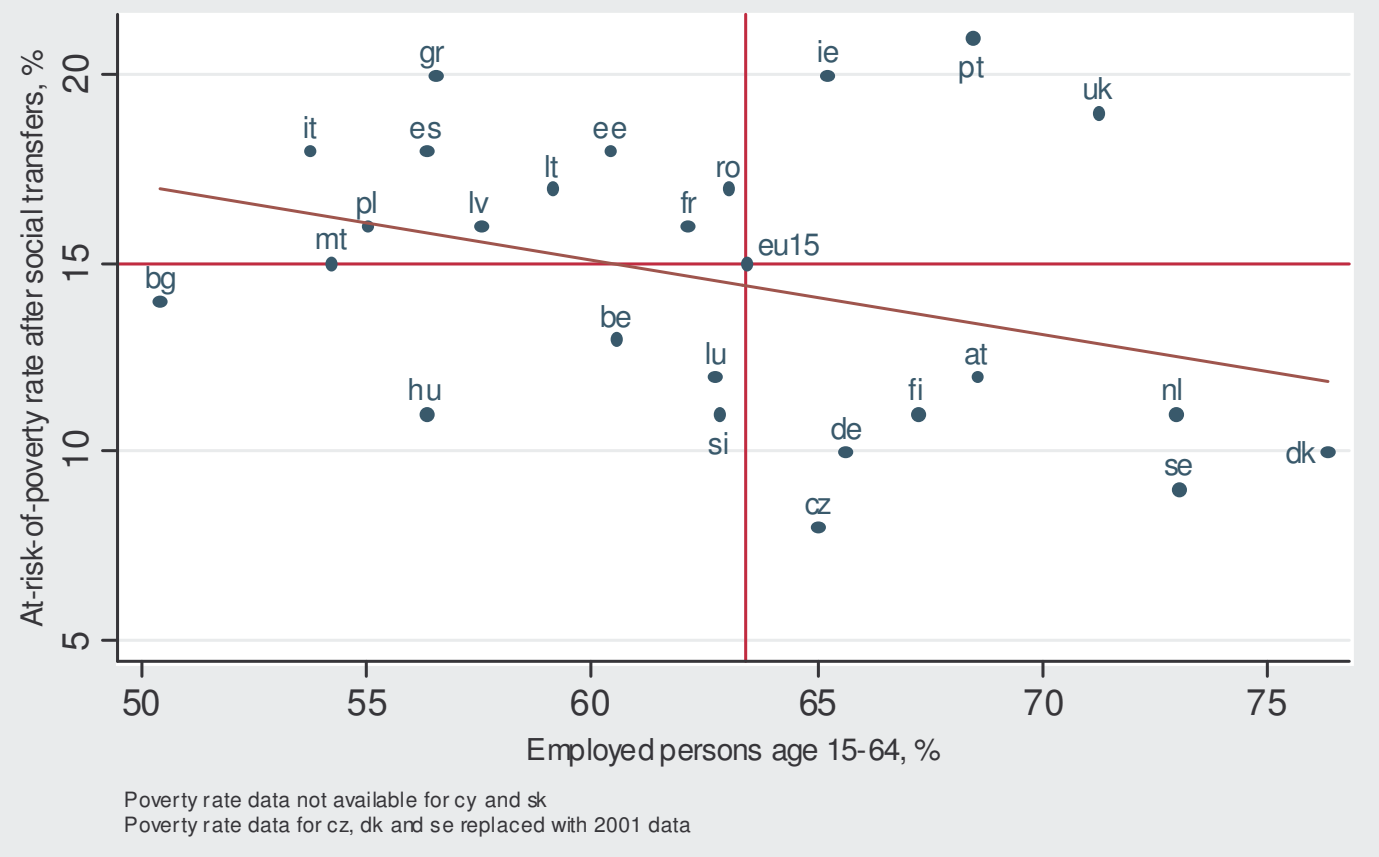

Figure 8

graph_1.1_2000-2005

EU27: Poverty Rate vs Employment Rate

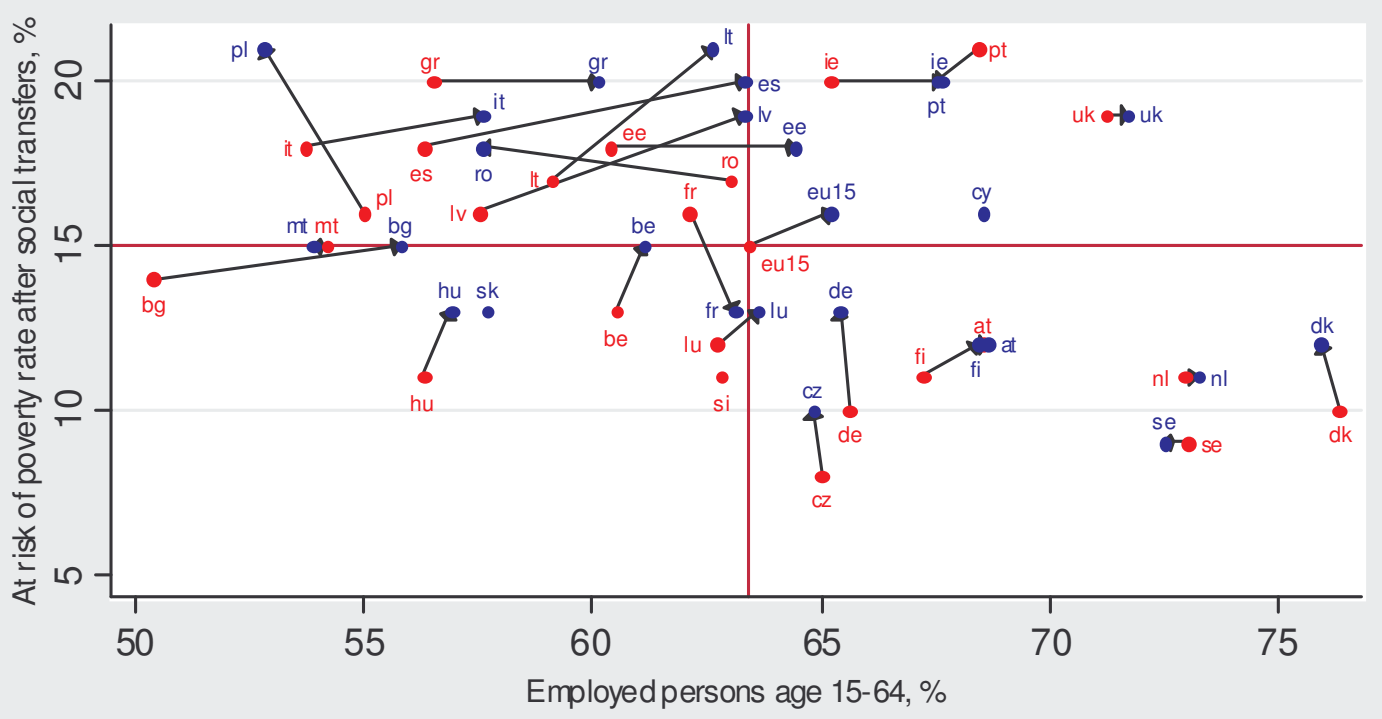

$2000-2005 \cdot 2000 \cdot 2005$

Poverty rate data not available for cy-2000, sk-2000, si-2005

Poverty rate data for dk-2000 and se-2000 replaced with 1999 data, for cz-2000 with 2001 data and bg-2005 with 2004 data 
Figure 9

graph_3.3_2005

Poverty risk vs Labor Market Expenditure (\% GDP)

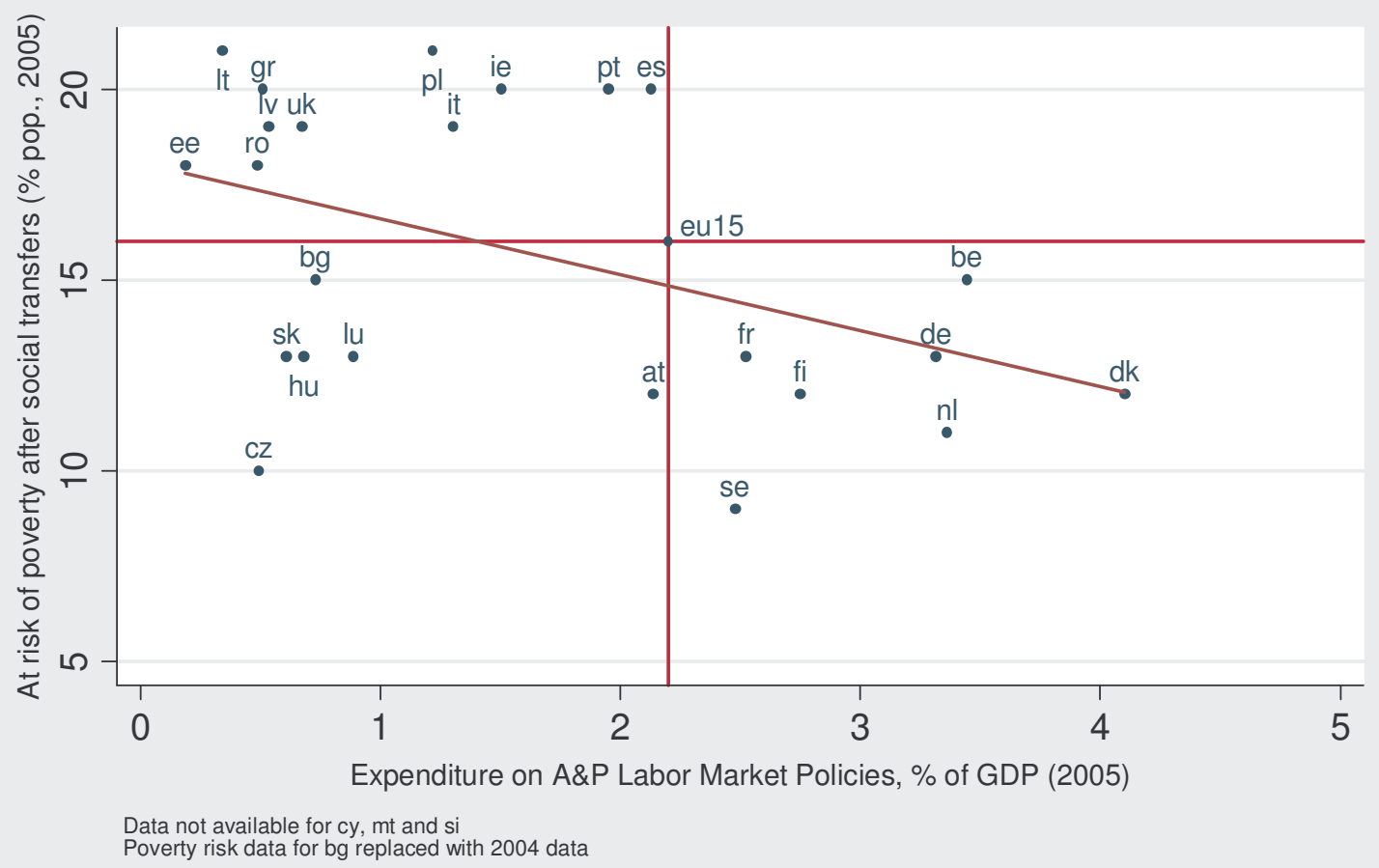

Figure 10

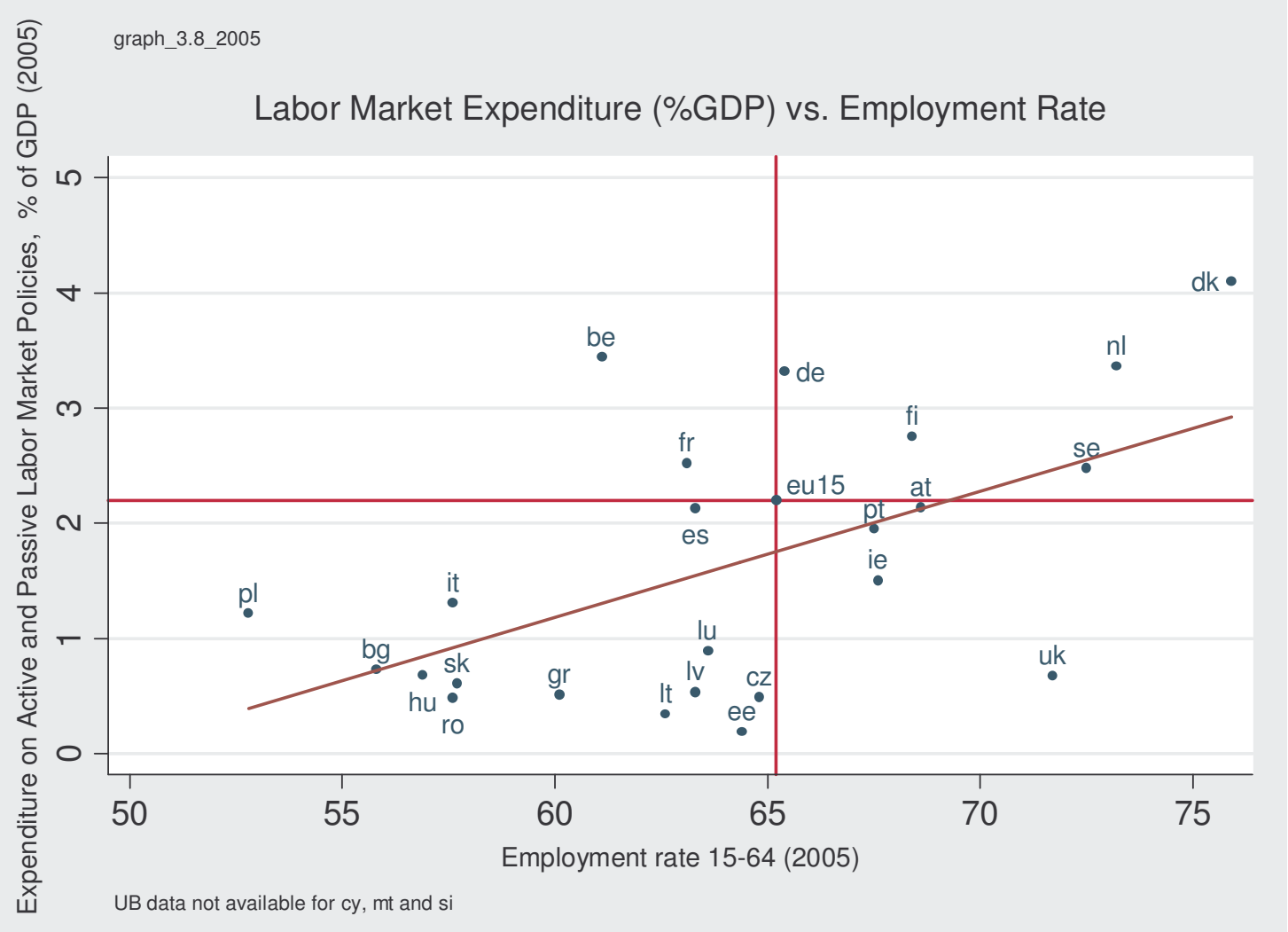


Figure 11

graph_3.9_2005

EPL vs Employment Rate

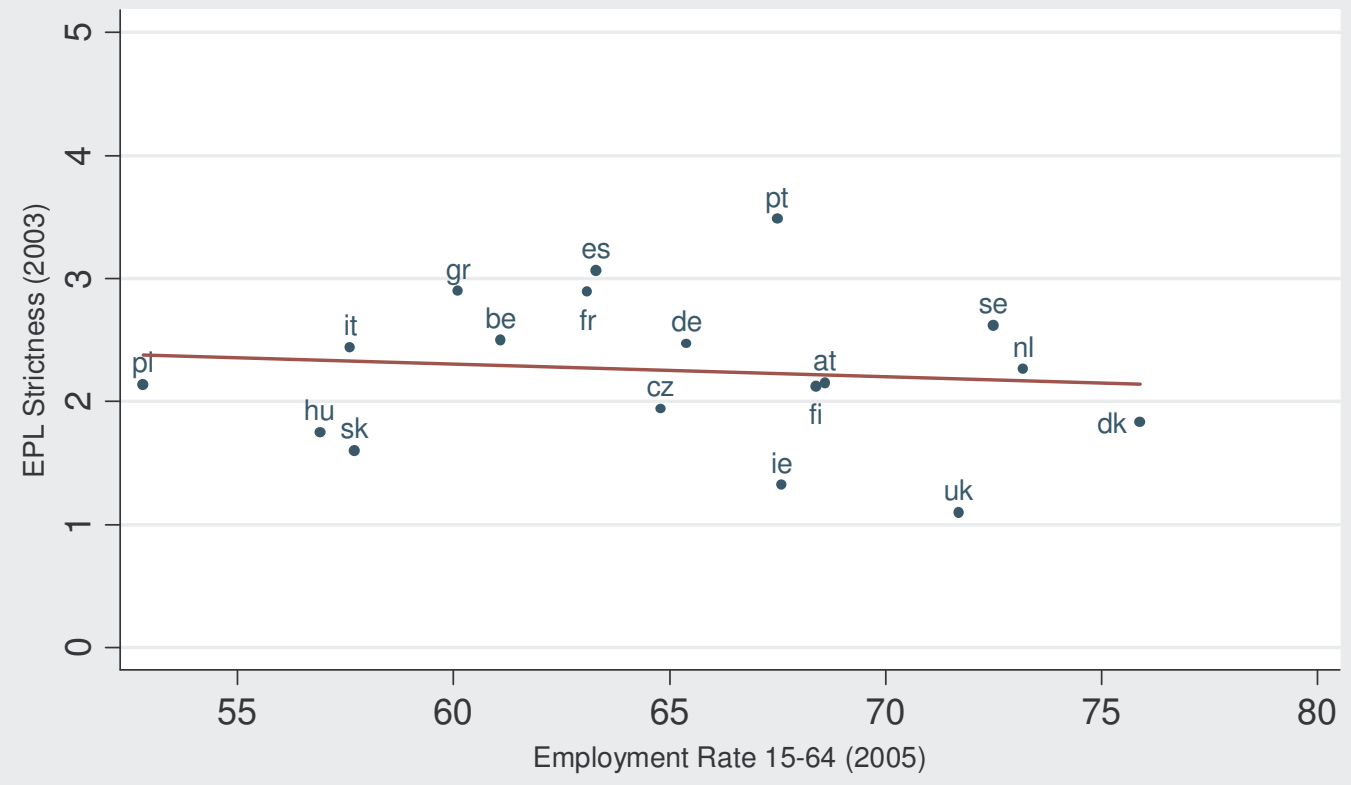

EPL Strictness data not available for bg, cy, ee, It, Iv, lu, mt, ro and si

Figure 12

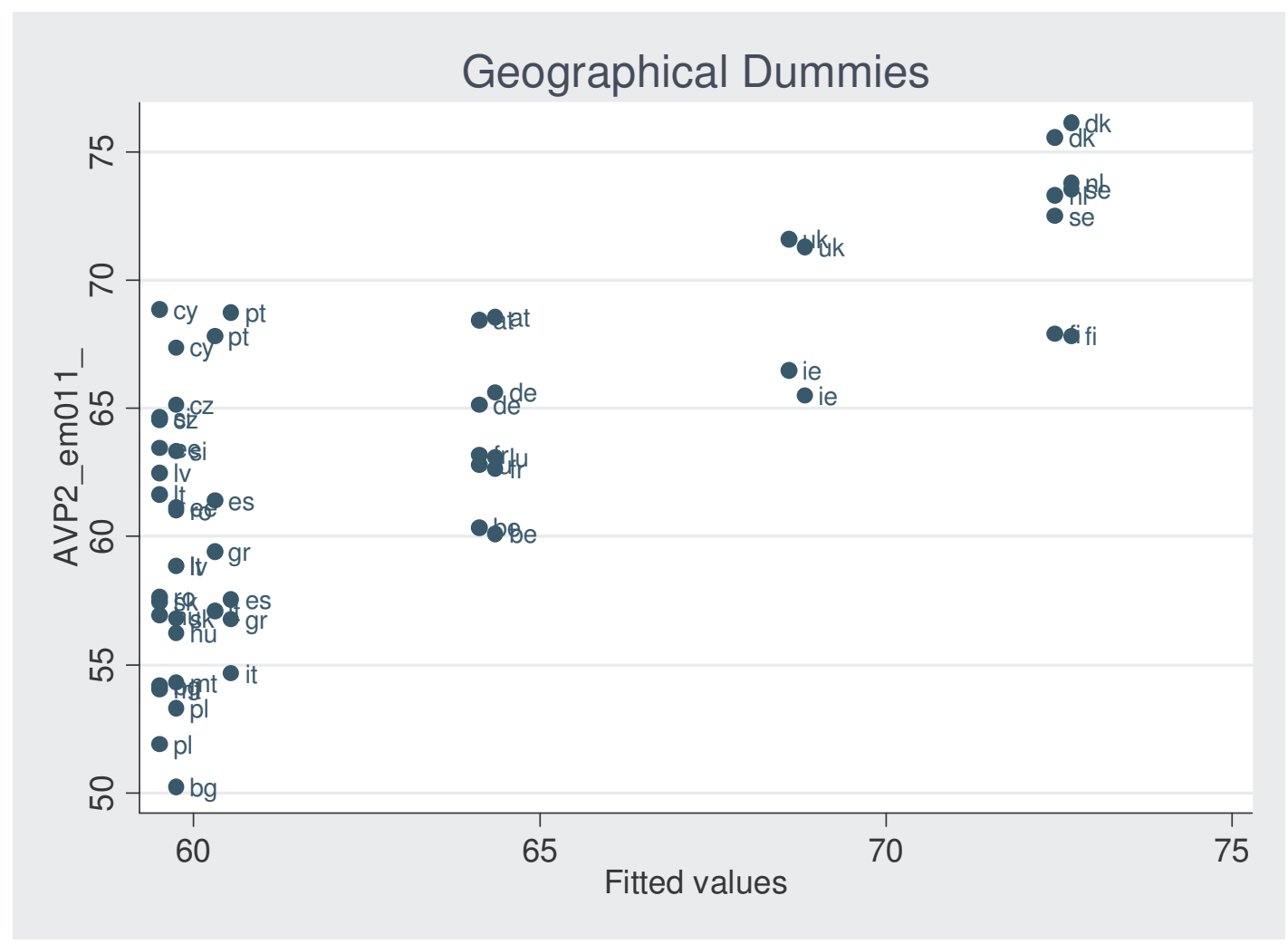


Figure 13

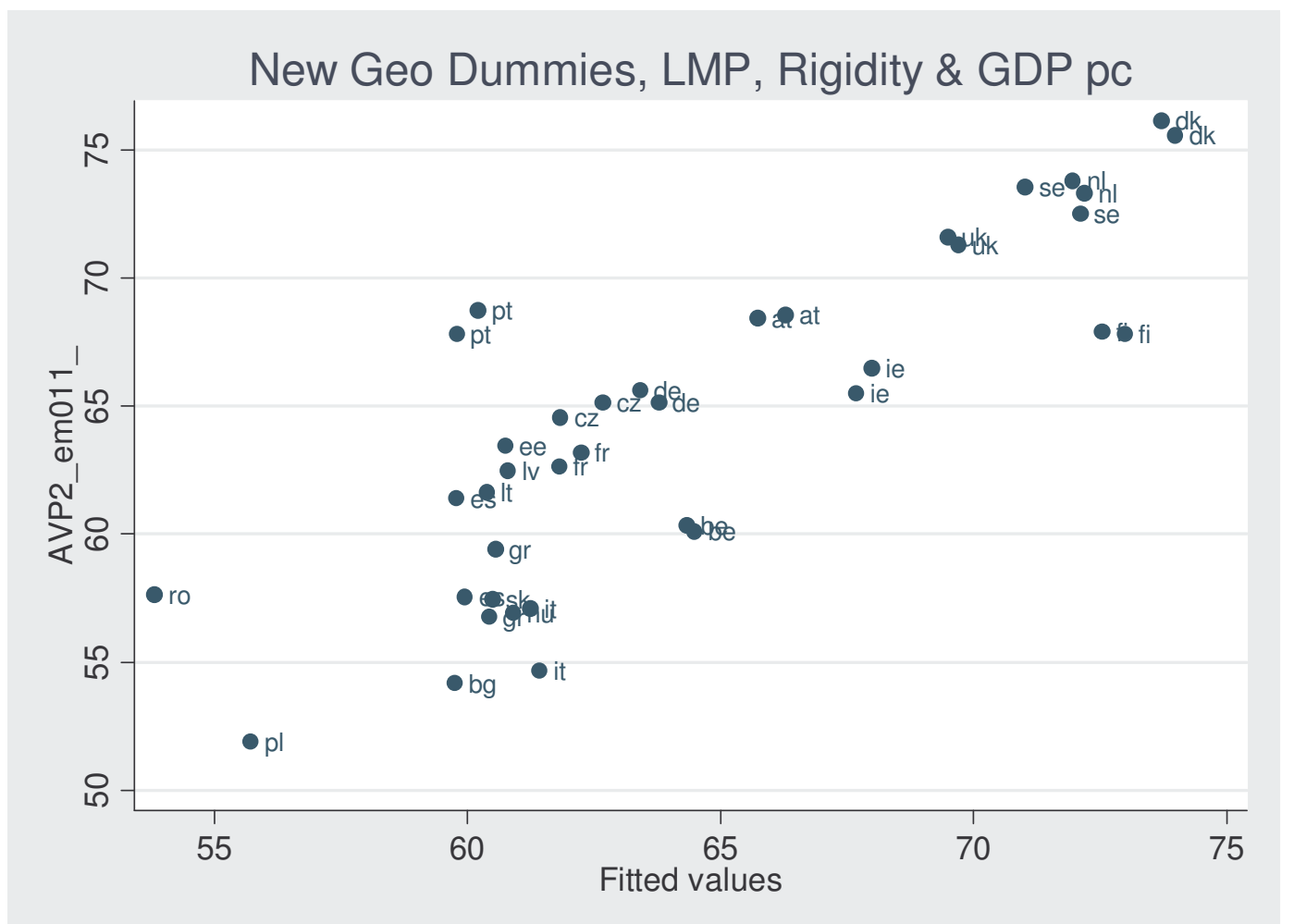

Figure 14

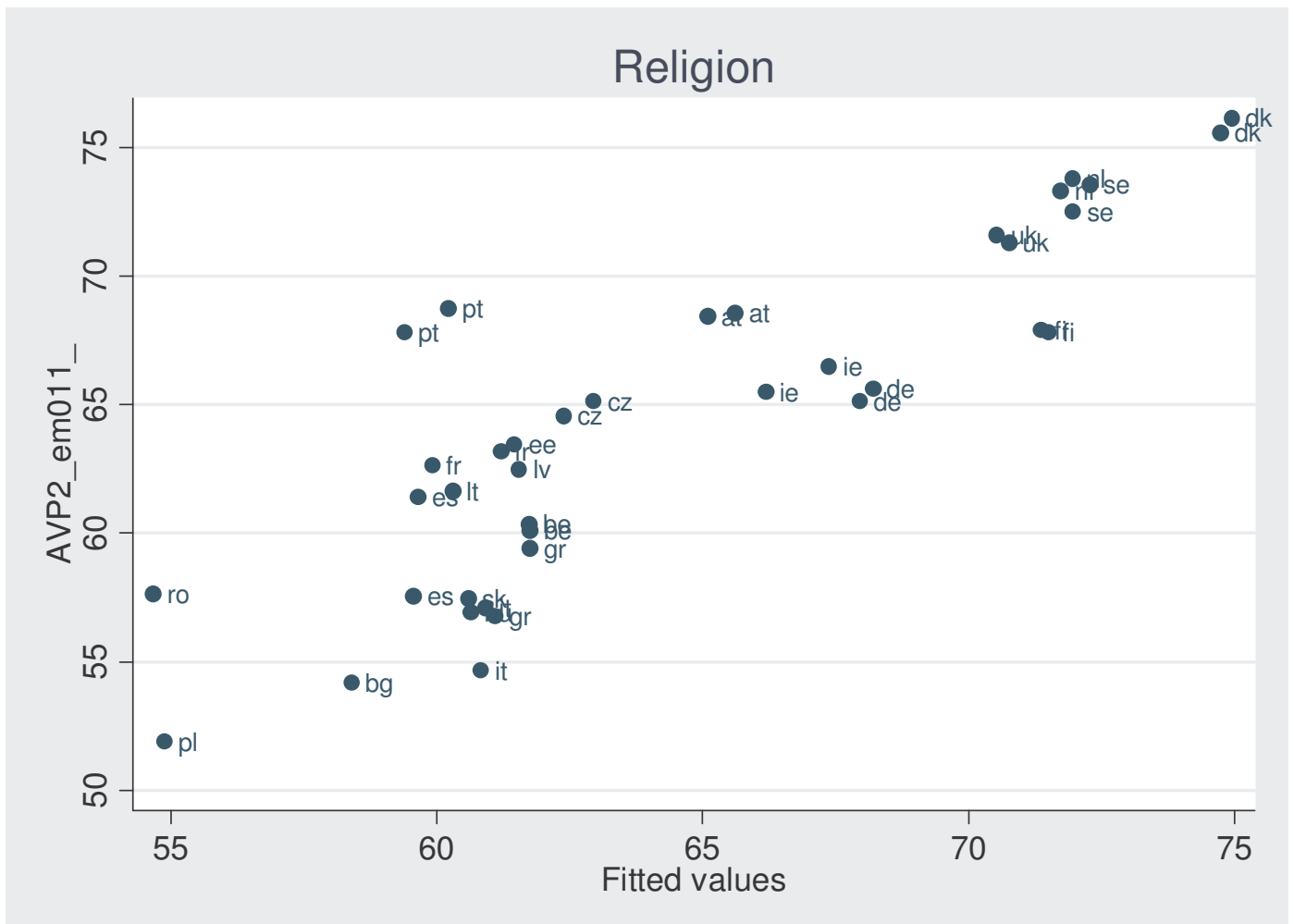


Figure 15

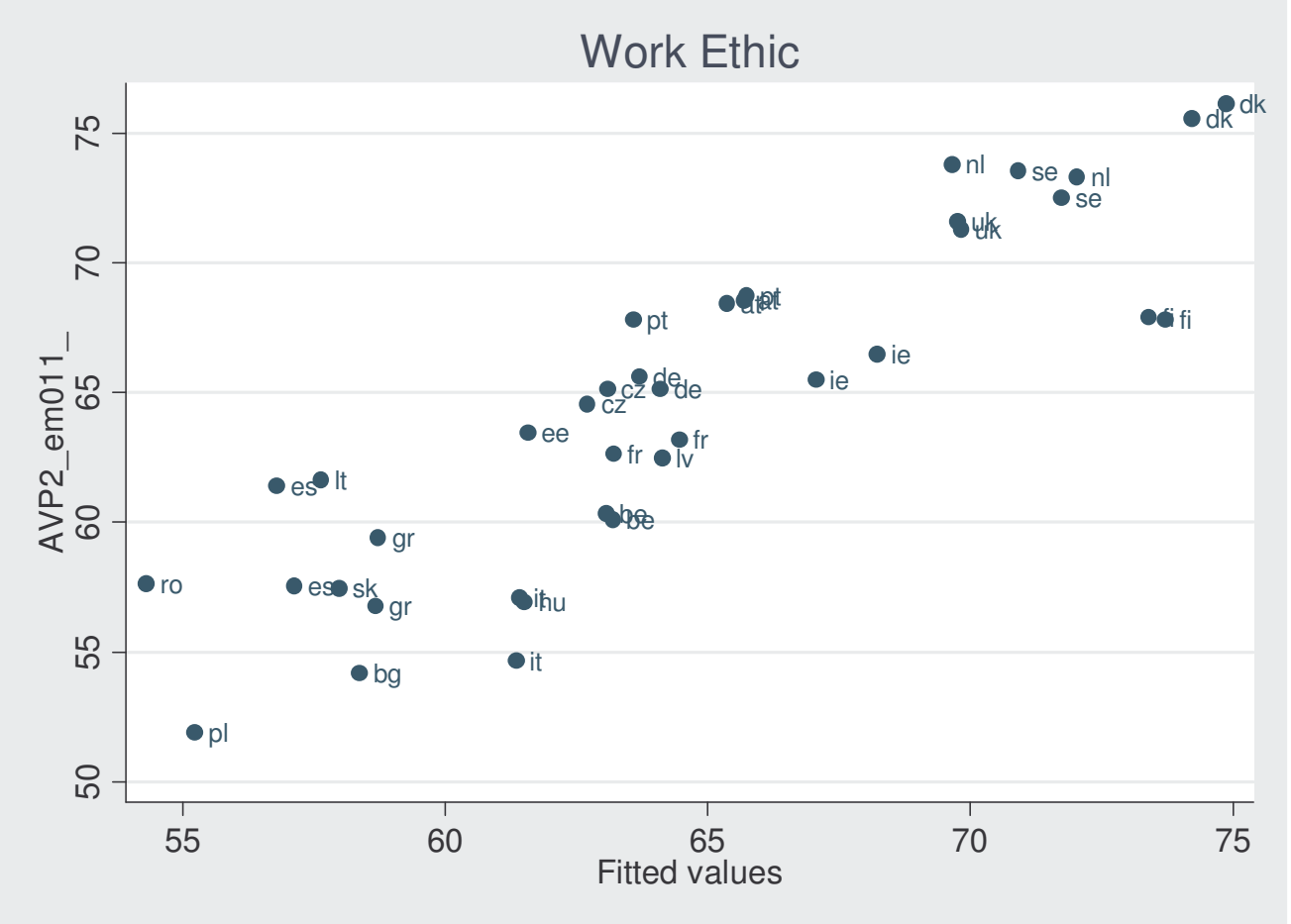


Table 1 - Labor Market Expenditures and Institutional Rigidities, 2000-2005

\begin{tabular}{|c|c|c|c|c|c|c|c|c|c|c|c|c|c|c|c|c|}
\hline & & \multicolumn{2}{|c|}{ Active ${ }^{a}$ LMP } & \multirow{2}{*}{$\begin{array}{l}\text { Rank } \\
2005 \\
\end{array}$} & \multicolumn{2}{|c|}{ Passive $^{b}$ LMP } & \multirow{2}{*}{$\begin{array}{l}\text { Rank } \\
2005\end{array}$} & \multicolumn{2}{|c|}{ Total $^{c}$ LMP } & \multirow{2}{*}{$\begin{array}{l}\text { Rank } \\
2005\end{array}$} & \multirow{2}{*}{$\begin{array}{l}\text { Rigidity } \\
\text { (WB) } \\
2003\end{array}$} & \multirow[t]{2}{*}{ Rank } & \multirow{2}{*}{$\begin{array}{c}\text { EPL }^{\mathrm{d}} \\
\text { OECD } \\
2003\end{array}$} & \multirow[t]{2}{*}{ Rank } & \multirow{2}{*}{$\begin{array}{c}\text { Pr. Market Reg. } \\
2003\end{array}$} & \multirow[t]{2}{*}{ Rant } \\
\hline & & 2000 & 2005 & & 2000 & 2005 & & 2000 & 2005 & & & & & & & \\
\hline $\begin{array}{l}\text { European Union } \\
\text { (15) }\end{array}$ & $\begin{array}{l}\mathrm{EU} \\
15 \\
\end{array}$ & 0.76 & 0.55 & $=$ & 1.25 & 1.41 & $=$ & 2.01 & 2.20 & $=$ & $=$ & $=$ & $=$ & $=$ & $=$ & $=$ \\
\hline Austria & at & 0.38 & 0.46 & 11 & 1.17 & 1.51 & 7 & 1.56 & 2.14 & 8 & 33 & 17 & 2.2 & 10 & 1.4 & 10 \\
\hline Belgium & be & 0.97 & 0.85 & 3 & 2.15 & 2.36 & 2 & 3.12 & 3.45 & 2 & 27 & 19 & 2.5 & 6 & 1.4 & 10 \\
\hline Bulgaria & bg &.. & 0.44 & 13 &.. & 0.22 & 21 &.. & 0.73 & 15 & 46 & 10 &.. & .. &.. &.. \\
\hline Czech R. & $\mathrm{cz}$ & .. & 0.12 & 20 & .. & 0.24 & 20 & .. & 0.49 & 21 & 20 & 21 & 1.9 & 13 & 1.7 & 5 \\
\hline Denmark & $\mathrm{dk}$ & 1.67 & 1.43 & 1 & 2.38 & 2.51 & 1 & 4.05 & 4.10 & 1 & 16 & 22 & 1.8 & 14 & 1.1 & 18 \\
\hline Estonia & ee & .. & 0.05 & 24 & & 0.12 & 23 & .. & 0.19 & 24 & 58 & 4 & & .. & 1.6 & 7 \\
\hline Finland & fi & 0.75 & 0.71 & 5 & 2.08 & 1.90 & 5 & 2.82 & 2.75 & 5 & 44 & 11 & 2.1 & 11 & 1.3 & 15 \\
\hline France & fr & 1.01 & 0.66 & 6 & 1.38 & 1.63 & 6 & 2.39 & 2.52 & 6 & 55 & 7 & 2.9 & 3 & 1.7 & 5 \\
\hline Germany & de & 0.99 & 0.62 & 7 & 1.89 & 2.35 & 3 & 2.88 & 3.32 & 4 & 44 & 11 & 2.5 & 6 & 1.4 & 10 \\
\hline Greece & gr & 0.26 & 0.06 & 23 & 0.43 & 0.44 & 15 & 0.69 & 0.51 & 20 & 58 & 4 & 2.9 & 3 & 1.8 & 4 \\
\hline Hungary & hu &.. & 0.20 & 16 &.. & 0.39 & 16 & .. & 0.68 & 16 & 33 & 17 & 1.7 & 15 & 2 & 2 \\
\hline Ireland & ie & 0.79 & 0.48 & 10 & 0.78 & 0.83 & 12 & 1.56 & 1.50 & 11 & 27 & 19 & 1.3 & 17 & 1.1 & 18 \\
\hline Italy & it & 0.55 & 0.46 & 11 & 0.62 & 0.82 & 13 & 1.16 & 1.31 & 12 & 53 & 8 & 2.4 & 8 & 1.9 & 3 \\
\hline Latvia & lv &.. & 0.15 & 18 & .. & 0.32 & 18 & .. & 0.54 & 19 & 62 & 2 & .. & .. &.. & .. \\
\hline Lithuania & lt &.. & 0.15 & 18 &.. & 0.12 & 23 &.. & 0.34 & 23 & 47 & 9 & .. & .. &.. & .. \\
\hline Luxembourg & lu &.. & 0.22 & 15 & 0.43 & 0.67 & 14 & .. & 0.89 & 14 &.. & .. & .. & .. & 1.3 & 15 \\
\hline Netherlands & $\mathrm{nl}$ & 1.08 & 0.85 & 3 & 2.03 & 2.02 & 4 & 3.12 & 3.36 & 3 & 42 & 13 & 2.3 & 9 & 1.4 & 10 \\
\hline Poland & $\mathrm{pl}$ &.. & 0.36 & 14 & .. & 0.86 & 11 & .. & 1.22 & 13 & 37 & 16 & 2.1 & 11 & 2.8 & 1 \\
\hline Portugal & $\mathrm{pt}$ & 0.35 & 0.52 & 9 & 0.82 & 1.29 & 9 & 1.18 & 1.95 & 10 & 56 & 6 & 3.5 & 1 & 1.6 & 7 \\
\hline Romania & ro &.. & 0.10 & 22 &.. & 0.36 & 17 &.. & 0.49 & 21 & 65 & 1 & & .. &.. &.. \\
\hline Slovakia & sk &.. & 0.17 & 17 &.. & 0.27 & 19 &.. & 0.61 & 18 & 38 & 15 & 1.6 & 16 & 1.4 & 10 \\
\hline Spain & es & 0.66 & 0.58 & 8 & 1.35 & 1.46 & 8 & 2.01 & 2.13 & 9 & 62 & 2 & 3.1 & 2 & 1.6 & 7 \\
\hline Sweden & se & 1.53 & 1.10 & 2 & 1.36 & 1.20 & 10 & 2.89 & 2.48 & 7 & 42 & 13 & 2.6 & 5 & 1.2 & 17 \\
\hline U.Kingdom & uk & 0.20 & 0.12 & 20 & 0.30 & 0.19 & 22 & 0.50 & 0.67 & 17 & 13 & 23 & 1.1 & 18 & 0.9 & 20 \\
\hline
\end{tabular}

Notes: Expenditure in Labor Market Programmes as \% of GDP. Rankings: from most generous or rigid to least.

Definition of expenditures: a) Active $=$ Eurostat categories 2-7 (Luxembourg: only 3-7) b) Passive $=$ cat. 8-9, c) Total = includes also exp. in labor market services (cat. 1), except for Luxembourg and Poland. Rank correlations: Between Total and EPL (RIG):-0.44 (-0.29); Between Active and Passive: 0.78; Between Active and EPL (RIG):-0.47 (-0.24); Between Passive and EPL (RIG): 0.13 (-0.20).

Sources: Expenditure data: Eurostat (n.a.: Cyprus, Malta, Slovenia); Rigidity : World Bank; EPL and Product Market Regulation: OECD (n.a.: Bulgaria, Cyprus, Estonia, Latvia, Lithuania, Malta, Slovenia), 
Table 2 - Labor Market Outcomes (2000 vs. 2005)

\begin{tabular}{|c|c|c|c|c|c|c|c|c|c|}
\hline & \multicolumn{3}{|c|}{2000} & \multicolumn{3}{|c|}{2005} & \multicolumn{3}{|c|}{ Change 2000-2005 } \\
\hline & $\begin{array}{c}\text { Empl. } \\
\text { rate }\end{array}$ & $\begin{array}{c}\text { Unempl. } \\
\text { rate }\end{array}$ & $\begin{array}{c}\text { Activity } \\
\text { rate }\end{array}$ & $\begin{array}{c}\text { Empl. } \\
\text { rate }\end{array}$ & $\begin{array}{c}\text { Unempl. } \\
\text { rate }\end{array}$ & $\begin{array}{c}\text { Activity } \\
\text { rate }\end{array}$ & $\begin{array}{c}\text { Empl. } \\
\text { rate }\end{array}$ & $\begin{array}{c}\text { Unempl. } \\
\text { rate }\end{array}$ & $\begin{array}{c}\text { Activity } \\
\text { rate }\end{array}$ \\
\hline European Union (15) & 63.4 & 7.6 & 69.2 & 65.2 & 7.9 & 71.0 & 1.8 & 0.3 & 1.8 \\
\hline Austria & 68.5 & 3.6 & 71.0 & 68.6 & 5.2 & 72.4 & 0.1 & 1.6 & 1.4 \\
\hline Belgium & 60.5 & 6.9 & 65.1 & 61.1 & 8.4 & 66.7 & 0.6 & 1.5 & 1.6 \\
\hline Bulgaria & 50.4 & 16.4 & 60.7 & 55.8 & 10.1 & 62.1 & 5.4 & -6.3 & 1.4 \\
\hline Cyprus & 65.7 & 4.9 & 69.1 & 68.5 & 5.2 & 72.4 & 2.8 & 0.3 & 3.3 \\
\hline Czech Republic & 65.0 & 8.7 & 71.3 & 64.8 & 7.9 & 70.4 & -0.2 & -0.8 & -0.9 \\
\hline Denmark & 76.3 & 4.3 & 80.0 & 75.9 & 4.8 & 79.8 & -0.4 & 0.5 & -0.2 \\
\hline Estonia & 60.4 & 12.8 & 70.2 & 64.4 & 7.9 & 70.1 & 4.0 & -4.9 & -0.1 \\
\hline Finland & 67.2 & 9.8 & 74.5 & 68.4 & 8.4 & 74.7 & 1.2 & -1.4 & 0.2 \\
\hline France & 62.1 & 9.1 & 68.7 & 63.1 & 9.6 & 69.5 & 1.0 & 0.5 & 0.8 \\
\hline Germany & 65.6 & 7.2 & 71.1 & 65.4 & 9.5 & 73.8 & -0.2 & 2.3 & 2.7 \\
\hline Greece & 56.5 & 11.2 & 63.8 & 60.1 & 9.8 & 66.8 & 3.6 & -1.4 & 3.0 \\
\hline Hungary & 56.3 & 6.4 & 60.1 & 56.9 & 7.2 & 61.3 & 0.6 & 0.8 & 1.2 \\
\hline Ireland & 65.2 & 4.2 & 68.2 & 67.6 & 4.3 & 70.8 & 2.4 & 0.1 & 2.6 \\
\hline Italy & 53.7 & 10.1 & 60.1 & 57.6 & 7.7 & 62.5 & 3.9 & -2.4 & 2.4 \\
\hline Latvia & 57.5 & 13.7 & 67.2 & 63.3 & 8.9 & 69.6 & 5.8 & -4.8 & 2.4 \\
\hline Lithuania & 59.1 & 16.4 & 70.8 & 62.6 & 8.3 & 68.4 & 3.5 & -8.1 & -2.4 \\
\hline Luxembourg & 62.7 & 2.3 & 64.1 & 63.6 & 4.5 & 66.6 & 0.9 & 2.2 & 2.5 \\
\hline Malta & 54.2 & 6.7 & 58.0 & 53.9 & 7.3 & 58.1 & -0.3 & 0.6 & 0.1 \\
\hline Netherlands & 72.9 & 2.8 & 75.2 & 73.2 & 4.7 & 76.9 & 0.3 & 1.9 & 1.7 \\
\hline Poland & 55.0 & 16.1 & 65.8 & 52.8 & 17.7 & 64.4 & -2.2 & 1.6 & -1.4 \\
\hline Portugal & 68.4 & 4.0 & 71.4 & 67.5 & 7.6 & 73.4 & -0.9 & 3.6 & 2.0 \\
\hline Romania & 63.0 & 7.2 & 68.4 & 57.6 & 7.2 & 62.3 & -5.4 & 0.0 & -6.1 \\
\hline Slovakia & 56.8 & 18.8 & 69.9 & 57.7 & 16.3 & 68.9 & 0.9 & -2.5 & -1.0 \\
\hline Slovenia & 62.8 & 6.7 & 67.5 & 66.0 & 6.5 & 70.7 & 3.2 & -0.2 & 3.2 \\
\hline Spain & 56.3 & 11.1 & 65.4 & 63.3 & 9.2 & 69.7 & 7.0 & -1.9 & 4.3 \\
\hline Sweden & 73.0 & 5.6 & 77.3 & 72.5 & 7.5 & 78.7 & -0.5 & 1.9 & 1.4 \\
\hline United Kingdom & 71.2 & 5.3 & 75.4 & 71.7 & 4.8 & 75.3 & 0.5 & -0.5 & -0.1 \\
\hline
\end{tabular}




\section{Legenda for Tables 3-8:}

\begin{tabular}{|c|c|}
\hline Dum_Nord & $=1$ for: Denmark, Finland, Netherlands and Sweden \\
\hline Dum_NMS & $\begin{array}{l}=1 \text { for: Bulgaria, Cyprus, Czech Republic, Estonia, Hungary, Latvia, Lithuania, Malta, Poland, Romania, Slovakia } \\
\text { and Slovenia }\end{array}$ \\
\hline Dum_Cont & = 1 for: Austria, Belgium, France, Germany and Luxembourg (Grand-Duché) \\
\hline Dum_Med & $=1$ for: Greece, Italy, Portugal and Spain \\
\hline Dum_FTR & $=1$ for: Bulgaria, Estonia, Latvia, Lithuania and Slovenia \\
\hline Dum_PoRo & $=1$ for: Poland and Romania \\
\hline Dum_CTE & = 1 for: Austria, Belgium, Czech Republic, France, Germany, Hungary, Luxembourg (Grand-Duché) and Slovakia \\
\hline Dum_MEL & $=1$ for: Cyprus, Greece, Italy, Malta, Portugal and Spain \\
\hline GDP pc.(lag) & $\begin{array}{l}=\text { Gross Domestic Product at Market Prices, Euro per inhabitant (at } 1995 \text { prices and exchange rates), at t-1 } \\
\text { (1999 and 2002) }\end{array}$ \\
\hline Rigidity & $=$ Index of Employment Rigidity, Doing Business Database, World Bank (see table 1) \\
\hline EPL & $=$ Employment Protection Legislation Index, OECD (see table 1) \\
\hline PMR & $=$ Product Market Regulation Index, OECD (see table 1 ) \\
\hline LMP27 & = Labor Market Polices, Active policies, items 2-7 Eurostat (see note 8) \\
\hline LMP89 & $=$ Labor Market Polices, Passive policies, items 8-9 Eurostat (see note 8) \\
\hline LMP19 & = Labor Market Polices, Overall Expenditures Eurostat (see note 8) \\
\hline ALMP_OECD & = Active Labor Market Polices, OECD \\
\hline APFH_OECD & $=$ Active + Passive + Family + Housing Polices, OECD \\
\hline Total_OECD & $=$ Total Social Policies, OECD \\
\hline Work & $=0$ for strongly agree with "people who do not want to work should work". $=1$ otherwise \\
\hline Religion & $=1$ for prevailing $(>50 \%)$ Catholic or Orthodox affiliation \\
\hline "var1"_X_var2" & interaction term between "var1" and "var2" \\
\hline \multicolumn{2}{|c|}{ Robust standard errors in parentheses. $\quad *$ significant at $10 \% ; * *$ significant at $5 \% ; * * *$ significant at $1 \%$} \\
\hline
\end{tabular}


Table 3. Modeling Employment Rates: LMP, Rigidity, Geography and Culture

\begin{tabular}{|c|c|c|c|c|c|c|c|c|c|c|}
\hline $\begin{array}{l}\text { Dependent variable: } \\
\text { EMPLOYMENT RATE }\end{array}$ & (1) & (2) & (3) & (4) & (5) & (6) & (7) & (8) & (9) & $(10)$ \\
\hline \multirow[t]{2}{*}{ Dum_Nord } & 3.850 & 3.850 & & & & 5.741 & 0.042 & -1.431 & 4.996 & 3.262 \\
\hline & $(2.664)$ & $(2.707)$ & & & & $(3.686)$ & $(4.490)$ & $(3.712)$ & $(4.074)$ & $(3.574)$ \\
\hline \multirow[t]{2}{*}{ Dum_NMS } & $-9.091 * * *$ & & & & & & & & & \\
\hline & $(2.799)$ & & & & & & & & & \\
\hline \multirow[t]{2}{*}{ Dum_Cont } & -4.471 & & & & & & & & & \\
\hline & $(2.709)$ & & & & & & & & & \\
\hline \multirow[t]{2}{*}{ Dum_Med } & $-8.292 * *$ & & & & & & & & & \\
\hline & $(3.347)$ & & & & & & & & & \\
\hline \multirow[t]{2}{*}{ Dum_FTR } & & $-8.130 * *$ & & & & -1.714 & -2.864 & $-7.838 * *$ & -6.938 & $-11.926 * *$ \\
\hline & & $(2.984)$ & & & & $(4.532)$ & $(4.183)$ & $(3.158)$ & $(5.701)$ & $(5.059)$ \\
\hline \multirow[t]{2}{*}{ Dum_PoRo } & & $-13.789 * * *$ & & & & -7.620 & $-8.246^{*}$ & $-13.207 * * *$ & -7.112 & $-12.307 * * *$ \\
\hline & & $(3.135)$ & & & & $(5.185)$ & $(4.595)$ & $(3.085)$ & $(5.198)$ & $(4.034)$ \\
\hline \multirow[t]{2}{*}{ Dum_CTE } & & $-5.520 * *$ & & & & -3.401 & $-3.953^{*}$ & $-5.486 * *$ & -3.627 & $-5.232 *$ \\
\hline & & $(2.601)$ & & & & $(2.614)$ & $(2.053)$ & $(2.386)$ & $(2.577)$ & $(2.883)$ \\
\hline \multirow[t]{2}{*}{ Dum_MEL } & & $-8.292 * *$ & & & & -3.550 & -3.832 & $-6.966^{*}$ & -6.560 & $-9.706 * *$ \\
\hline & & $(3.401)$ & & & & $(4.722)$ & $(4.498)$ & $(3.996)$ & $(4.688)$ & $(4.038)$ \\
\hline \multirow[t]{2}{*}{ GDP pc.(lag) } & & & $0.427 * * *$ & & $0.303 * *$ & 0.262 & 0.282 & & 0.291 & \\
\hline & & & $(0.106)$ & & $(0.130)$ & $(0.194)$ & $(0.199)$ & & $(0.197)$ & \\
\hline \multirow[t]{2}{*}{ Rigidity } & & & & $-0.160 * *$ & $-0.127 *$ & -0.080 & -0.047 & -0.018 & 0.018 & 0.046 \\
\hline & & & & $(0.069)$ & $(0.067)$ & $(0.070)$ & $(0.064)$ & $(0.054)$ & $(0.093)$ & $(0.084)$ \\
\hline \multirow[t]{2}{*}{ LMP27 } & & & & $6.822 * * *$ & 1.737 & -3.212 & 0.538 & 4.540 & 16.323 & $19.880 * *$ \\
\hline & & & & $(2.141)$ & $(3.104)$ & $(4.216)$ & $(4.461)$ & $(2.869)$ & $(9.519)$ & $(8.532)$ \\
\hline \multirow[t]{2}{*}{ Religion_X_LMP27 } & & & & & & & $-7.164 * *$ & $-6.857 * *$ & & \\
\hline & & & & & & & $(3.304)$ & $(2.721)$ & & \\
\hline \multirow[t]{2}{*}{ Work_X_LMP27 } & & & & & & & & & $-0.536 *$ & $-0.517 * *$ \\
\hline & & & & & & & & & $(0.262)$ & $(0.241)$ \\
\hline \multirow[t]{2}{*}{ Work } & & & & & & & & & $0.532 * *$ & $0.510 * *$ \\
\hline & & & & & & & & & $(0.233)$ & $(0.214)$ \\
\hline Observations & 38 & 38 & 38 & 38 & 38 & 38 & 38 & 38 & 38 & 38 \\
\hline Adjusted R-squared & 0.58 & 0.59 & 0.36 & 0.36 & 0.41 & 0.59 & 0.65 & 0.62 & 0.67 & 0.64 \\
\hline RMSE & 4.15 & 4.11 & 5.12 & 5.15 & 4.92 & 4.10 & 3.81 & 3.96 & 3.69 & 3.87 \\
\hline
\end{tabular}


Table 4. Modeling Employment Rates: substituting Rigidity with EPL and Product Market Regulation

\begin{tabular}{|c|c|c|c|c|c|c|c|}
\hline \multirow[t]{2}{*}{$\begin{array}{l}\text { Dependent variable: } \\
\text { EMPLOYMENT RATE }\end{array}$} & \multicolumn{4}{|c|}{ "Institution" = Employment Protection Legislation (EPL) } & \multicolumn{3}{|c|}{$\begin{array}{l}\text { "Institution" = Product Market } \\
\text { Regulation (PMR) }\end{array}$} \\
\hline & $(1)$ & (1bis) & $(2)$ & (3) & $(4)$ & (5) & $(6)$ \\
\hline \multirow[t]{2}{*}{ Dum_Nord } & 3.081 & 4.095 & -1.059 & 4.286 & $6.706 *$ & 2.850 & $6.253^{*}$ \\
\hline & (3.613) & $(3.602)$ & $(4.159)$ & $(4.078)$ & (3.609) & $(4.980)$ & $(3.263)$ \\
\hline \multirow[t]{2}{*}{ Dum_PoRo } & $-15.598 * * *$ & $-15.049 * * *$ & $-14.422 * * *$ & $-11.854 * *$ & -2.974 & -4.633 & -2.366 \\
\hline & $(4.527)$ & $(4.516)$ & $(4.656)$ & $(4.407)$ & $(7.381)$ & $(8.066)$ & $(6.465)$ \\
\hline \multirow[t]{2}{*}{ Dum_CTE } & $-5.799 * *$ & -3.399 & $-5.641 *$ & -4.143 & -0.181 & -1.145 & 0.116 \\
\hline & $(2.562)$ & $(2.928)$ & $(2.713)$ & $(2.494)$ & $(3.792)$ & $(4.138)$ & (3.409) \\
\hline \multirow[t]{2}{*}{ Dum_MEL } & $-10.597 * * *$ & $-10.289 * * *$ & $-9.346 * *$ & $-8.858 * *$ & -1.575 & -2.065 & -1.979 \\
\hline & $(3.170)$ & $(3.292)$ & $(3.403)$ & $(3.591)$ & $(4.978)$ & $(5.205)$ & $(3.470)$ \\
\hline \multirow[t]{2}{*}{ GDP pc.(lag) } & 0.072 & -0.007 & 0.125 & 0.187 & -0.035 & -0.010 & -0.101 \\
\hline & $(0.289)$ & $(0.286)$ & $(0.290)$ & $(0.262)$ & $(0.118)$ & $(0.122)$ & $(0.117)$ \\
\hline \multirow[t]{2}{*}{ "Institution" } & $3.508^{*}$ & $8.366 * * *$ & 3.253 & $2.716 *$ & $-7.221 *$ & -6.047 & $-7.181 * *$ \\
\hline & $(1.879)$ & $(2.835)$ & $(1.901)$ & $(1.512)$ & $(4.106)$ & $(4.628)$ & $(3.408)$ \\
\hline \multirow[t]{2}{*}{ LMP27 } & 0.290 & $20.692 * *$ & 2.792 & $17.886 * *$ & 0.119 & 2.583 & $14.733 * *$ \\
\hline & $(5.913)$ & $(9.353)$ & $(5.770)$ & $(7.250)$ & $(2.509)$ & $(2.936)$ & $(6.581)$ \\
\hline \multirow[t]{2}{*}{ "Institution"_X_LMP27 } & & $-8.623 * *$ & & & & & \\
\hline & & $(3.280)$ & & & & & \\
\hline \multirow[t]{2}{*}{ Religion_X_LMP27 } & & & $-6.132 *$ & & & -4.471 & \\
\hline & & & $(3.317)$ & & & $(3.305)$ & \\
\hline \multirow[t]{2}{*}{ Work_X_LMP27 } & & & & $-0.521 * *$ & & & $-0.347 * *$ \\
\hline & & & & $(0.196)$ & & & $(0.150)$ \\
\hline \multirow[t]{2}{*}{ Work } & & & & $0.516 * * *$ & & & $0.404 * *$ \\
\hline & & & & $(0.171)$ & & & $(0.149)$ \\
\hline Observations & 33 & 33 & 33 & 33 & 34 & 34 & 34 \\
\hline Adjusted R-squared & 0.65 & 0.69 & 0.70 & 0.74 & 0.66 & 0.68 & 0.73 \\
\hline RMSE & 3.82 & 3.60 & 3.57 & 3.30 & 3.70 & 3.61 & 3.31 \\
\hline
\end{tabular}

The Dummy for Fast Transition Countries (BG, EE, LT, LV, SI) is omitted because there are no observations for these countries in the sample. 
Table 5. Modeling Employment Rates: substituting Active LMP (2-7) with Total LMP (1-9)

\begin{tabular}{|c|c|c|c|c|c|c|c|c|c|}
\hline \multirow{2}{*}{$\begin{array}{l}\text { Dependent variable: } \\
\text { EMPLOYMENT RATE }\end{array}$} & \multicolumn{3}{|c|}{ Institution: Rigidity } & \multicolumn{3}{|c|}{ Institution: EPL } & \multicolumn{3}{|c|}{ Institution: PMR } \\
\hline & $(1)$ & $(2)$ & $(3)$ & $(4)$ & $(5)$ & $(6)$ & $(7)$ & $(8)$ & $(9)$ \\
\hline \multirow[t]{2}{*}{ Dum_Nord } & 6.088* & 3.283 & $7.533 * *$ & 3.383 & 0.784 & 4.908 & 6.683* & 4.439 & $6.486 * *$ \\
\hline & $(2.948)$ & $(2.611)$ & $(3.103)$ & $(3.393)$ & $(4.042)$ & $(3.278)$ & $(3.402)$ & $(4.103)$ & $(3.042)$ \\
\hline \multirow[t]{2}{*}{ Dum_PoRo } & -5.914 & -5.407 & -1.793 & $-15.242 * *$ & $-14.420 * *$ & $-11.677^{*}$ & -3.021 & -3.276 & -2.823 \\
\hline & $(4.087)$ & $(3.953)$ & $(5.390)$ & $(5.745)$ & $(6.143)$ & $(5.996)$ & $(7.313)$ & $(7.519)$ & $(6.544)$ \\
\hline \multirow[t]{2}{*}{ Dum_CTE } & -2.201 & -2.044 & -0.331 & -5.613 & -5.394 & -3.763 & -0.220 & -0.461 & -0.247 \\
\hline & $(2.089)$ & $(1.962)$ & $(2.341)$ & $(3.618)$ & $(3.968)$ & $(3.649)$ & $(3.889)$ & $(4.029)$ & $(3.520)$ \\
\hline \multirow[t]{2}{*}{ Dum_MEL } & -2.193 & -1.666 & -1.275 & $-10.391 * *$ & $-9.668 * *$ & $-8.967 *$ & -1.605 & -1.506 & -2.383 \\
\hline & $(3.711)$ & $(3.814)$ & $(3.993)$ & $(3.793)$ & $(4.164)$ & $(4.921)$ & $(4.936)$ & $(4.953)$ & $(3.598)$ \\
\hline \multirow[t]{2}{*}{ GDP pc.(lag) } & 0.312 & 0.335 & $0.439 *$ & 0.094 & 0.116 & 0.186 & -0.036 & -0.025 & -0.115 \\
\hline & $(0.210)$ & $(0.216)$ & $(0.219)$ & $(0.354)$ & $(0.379)$ & $(0.343)$ & $(0.114)$ & $(0.117)$ & $(0.107)$ \\
\hline \multirow[t]{2}{*}{ Institution } & -0.092 & -0.084 & -0.071 & $3.497^{*}$ & $3.512^{*}$ & $2.967^{*}$ & $-7.205^{*}$ & -6.816 & $-7.016^{*}$ \\
\hline & $(0.054)$ & $(0.050)$ & $(0.055)$ & $(1.794)$ & $(1.815)$ & $(1.616)$ & $(4.103)$ & $(4.366)$ & $(3.415)$ \\
\hline \multirow[t]{2}{*}{ LMP: $1-9$} & -1.214 & -0.486 & 2.719 & -0.108 & 0.572 & $6.871 * *$ & 0.052 & 0.654 & $6.247 * *$ \\
\hline & $(1.790)$ & $(1.587)$ & $(3.008)$ & $(2.433)$ & $(2.655)$ & $(3.020)$ & $(0.890)$ & $(0.876)$ & $(2.752)$ \\
\hline \multirow[t]{2}{*}{ Religion_X_LMP19 } & & $-1.401^{*}$ & & & -1.342 & & & -0.997 & \\
\hline & & $(0.728)$ & & & $(0.985)$ & & & $(0.925)$ & \\
\hline \multirow[t]{2}{*}{ Work_X_LMP19 } & & & -0.121 & & & $-0.196 * *$ & & & $-0.144 * *$ \\
\hline & & & $(0.086)$ & & & $(0.073)$ & & & $(0.062)$ \\
\hline \multirow[t]{2}{*}{ Work } & & & 0.413 & & & $0.575 * *$ & & & $0.474 * *$ \\
\hline & & & $(0.287)$ & & & $(0.210)$ & & & $(0.175)$ \\
\hline Observations & 38 & 38 & 38 & 33 & 33 & 33 & 34 & 34 & 34 \\
\hline Adjusted R-squared & 0.60 & 0.61 & 0.63 & 0.65 & 0.67 & 0.74 & 0.66 & 0.67 & 0.73 \\
\hline RMSE & 4.08 & 4.01 & 3.90 & 3.82 & 3.74 & 3.32 & 3.70 & 3.69 & 3.30 \\
\hline
\end{tabular}

The Dummy for Fast Transition Countries (BG, EE, LT, LV, SI) is omitted from columns 4-9 because there are no observations from these countries in this sample. 
Table 6. Modeling Employment Rates: substituting Active LMP (2-7) with Passive LMP (8-9)

\begin{tabular}{|c|c|c|c|c|c|c|c|c|c|}
\hline \multirow{2}{*}{$\begin{array}{l}\text { Dependent variable: } \\
\text { EMPLOYMENT RATE }\end{array}$} & \multicolumn{3}{|c|}{ "Institution": Rigidity } & \multicolumn{3}{|c|}{ "Institution": EPL } & \multicolumn{3}{|c|}{ "Institution": PMR } \\
\hline & (1) & $(2)$ & (3) & (4) & (5) & (6) & (7) & (8) & (9) \\
\hline \multirow[t]{2}{*}{ Dum_Nord } & $5.657 * *$ & $3.843^{*}$ & $6.912 * *$ & 3.669 & 1.819 & $5.300 * *$ & $7.021 * *$ & 5.631 & $7.512 * *$ \\
\hline & $(2.557)$ & $(1.995)$ & $(2.767)$ & $(2.500)$ & $(2.537)$ & $(2.430)$ & $(3.216)$ & $(3.464)$ & $(2.675)$ \\
\hline \multirow[t]{2}{*}{ Dum_PoRo } & -5.959 & -5.393 & -2.164 & $-14.735 * *$ & $-13.884 * *$ & $-11.398 *$ & -2.614 & -2.436 & -1.950 \\
\hline & $(4.273)$ & $(4.318)$ & $(5.770)$ & $(5.326)$ & $(5.611)$ & $(6.048)$ & $(7.446)$ & $(7.521)$ & $(6.496)$ \\
\hline \multirow[t]{2}{*}{ Dum_CTE } & -2.249 & -2.039 & -0.502 & -5.295 & -5.021 & -3.460 & 0.032 & 0.022 & 0.313 \\
\hline & $(2.173)$ & $(2.145)$ & $(2.586)$ & $(3.363)$ & $(3.607)$ & $(3.683)$ & $(3.986)$ & $(4.082)$ & $(3.447)$ \\
\hline \multirow[t]{2}{*}{ Dum_MEL } & -2.198 & -1.682 & -1.243 & $-10.094 * *$ & $-9.501 * *$ & -8.921 & -1.368 & -1.116 & -1.971 \\
\hline & $(3.757)$ & $(3.938)$ & $(4.320)$ & $(3.710)$ & $(4.090)$ & $(5.212)$ & $(4.987)$ & $(4.981)$ & $(3.593)$ \\
\hline \multirow[t]{2}{*}{ GDP pc.(lag) } & 0.282 & 0.305 & $0.382^{*}$ & 0.119 & 0.143 & 0.175 & -0.030 & -0.021 & -0.110 \\
\hline & $(0.199)$ & $(0.211)$ & $(0.219)$ & $(0.302)$ & $(0.317)$ & $(0.313)$ & $(0.118)$ & $(0.122)$ & $(0.112)$ \\
\hline \multirow[t]{2}{*}{ "Institution" } & $-0.093 *$ & $-0.089 *$ & -0.080 & $3.509 *$ & $3.631^{*}$ & $3.065 *$ & $-7.327^{*}$ & -7.198 & $-7.329 * *$ \\
\hline & $(0.054)$ & $(0.051)$ & $(0.058)$ & $(1.816)$ & $(1.834)$ & $(1.686)$ & $(4.161)$ & $(4.339)$ & $(3.374)$ \\
\hline \multirow[t]{2}{*}{ LMP89 } & -1.330 & -0.621 & 4.108 & -0.495 & 0.244 & $12.191 * *$ & -0.162 & 0.443 & $10.735^{* *}$ \\
\hline & $(2.446)$ & $(2.058)$ & $(5.146)$ & $(2.829)$ & $(2.936)$ & $(4.629)$ & $(1.311)$ & $(1.115)$ & $(4.583)$ \\
\hline \multirow[t]{2}{*}{ Religion_X_LMP89 } & & -1.553 & & & -1.644 & & & -1.106 & \\
\hline & & $(1.122)$ & & & $(1.289)$ & & & $(1.186)$ & \\
\hline \multirow[t]{2}{*}{ Work_X_LMP89 } & & & -0.162 & & & $-0.341 * *$ & & & $-0.262 * *$ \\
\hline & & & $(0.154)$ & & & $(0.120)$ & & & $(0.107)$ \\
\hline \multirow[t]{2}{*}{ Work } & & & 0.366 & & & $0.623 * *$ & & & $0.523 * *$ \\
\hline & & & $(0.317)$ & & & $(0.228)$ & & & $(0.190)$ \\
\hline Observations & 38 & 38 & 38 & 33 & 33 & 33 & 34 & 34 & 34 \\
\hline Adjusted R-squared & 0.59 & 0.59 & 0.61 & 0.65 & 0.66 & 0.74 & 0.67 & 0.66 & 0.74 \\
\hline RMSE & 4.10 & 4.09 & 3.98 & 3.82 & 3.79 & 3.30 & 3.70 & 3.73 & 3.28 \\
\hline
\end{tabular}

The Dummy for Fast Transition Countries (BG, EE, LT, LV, SI) is omitted from columns 4-9 because there are no observations from these countries in this sample. 
Table 7. Modeling Employment Rates: Substituting Eurostat with OECD Active LMP

\begin{tabular}{|c|c|c|c|c|c|c|c|c|c|}
\hline \multirow{2}{*}{$\begin{array}{l}\text { Dependent variable: } \\
\text { EMPLOYMENT RATE }\end{array}$} & \multicolumn{3}{|c|}{ "Institution": Rigidity } & \multicolumn{3}{|c|}{ "Institution": EPL } & \multicolumn{3}{|c|}{ "Institution": PMR } \\
\hline & $(1)$ & $(2)$ & (3) & (4) & (5) & (6) & (7) & $(8)$ & (9) \\
\hline \multirow[t]{2}{*}{ Dum_Nord } & 5.477 & 1.349 & 4.029 & 4.924 & 1.177 & $5.382 *$ & 6.435 & 1.915 & 5.467 \\
\hline & $(3.210)$ & $(3.518)$ & $(2.917)$ & $(3.055)$ & $(3.924)$ & $(2.879)$ & $(4.234)$ & $(5.422)$ & $(3.836)$ \\
\hline \multirow[t]{2}{*}{ Dum_PoRo } & $-7.538 * *$ & $-7.971 * *$ & $-7.264^{*}$ & $-10.882 * * *$ & $-10.670 * * *$ & $-7.818 * * *$ & -1.080 & -2.664 & -0.128 \\
\hline & $(3.429)$ & $(2.884)$ & $(3.713)$ & $(2.323)$ & $(2.600)$ & $(2.618)$ & $(11.629)$ & $(11.595)$ & $(9.123)$ \\
\hline \multirow[t]{2}{*}{ Dum_CTE } & -2.849 & -3.127 & -3.600 & $-4.919 * *$ & $-4.755^{*}$ & -3.337 & -1.439 & -1.927 & -1.429 \\
\hline & $(3.188)$ & $(2.593)$ & $(2.929)$ & $(1.946)$ & $(2.282)$ & $(2.129)$ & $(5.119)$ & $(4.925)$ & $(4.486)$ \\
\hline \multirow[t]{2}{*}{ Dum_MEL } & -2.406 & -2.841 & -8.541 & $-11.268 * * *$ & $-10.209 * * *$ & $-10.727 * * *$ & -3.459 & -3.520 & -4.063 \\
\hline & $(5.730)$ & $(5.400)$ & $(6.104)$ & $(2.629)$ & $(3.003)$ & $(3.520)$ & $(6.994)$ & $(6.828)$ & $(4.724)$ \\
\hline \multirow[t]{2}{*}{ GDP pc.(lag) } & 0.270 & 0.247 & 0.344 & 0.201 & 0.186 & 0.271 & 0.019 & 0.030 & -0.062 \\
\hline & $(0.242)$ & $(0.267)$ & $(0.235)$ & $(0.254)$ & $(0.284)$ & $(0.232)$ & $(0.206)$ & $(0.202)$ & $(0.212)$ \\
\hline \multirow[t]{2}{*}{ "Institution" } & -0.140 & -0.110 & 0.029 & $4.030 *$ & 3.597 & $3.683 * *$ & -4.790 & -3.919 & -4.473 \\
\hline & $(0.085)$ & $(0.080)$ & $(0.131)$ & $(1.948)$ & $(2.096)$ & $(1.605)$ & $(5.108)$ & $(5.274)$ & $(3.900)$ \\
\hline \multirow[t]{2}{*}{ ALMP_OECD } & -1.164 & 1.713 & $25.822 *$ & -2.660 & 0.363 & $23.378 * *$ & -0.085 & 2.972 & $18.574^{*}$ \\
\hline & $(4.587)$ & $(4.992)$ & $(12.779)$ & $(4.639)$ & $(5.477)$ & $(8.358)$ & $(2.828)$ & $(3.032)$ & $(10.637)$ \\
\hline \multirow[t]{2}{*}{ Religion_X_ALMP_OECD } & & $-4.229 *$ & & & -4.058 & & & -4.492 & \\
\hline & & $(2.327)$ & & & $(2.641)$ & & & $(2.829)$ & \\
\hline \multirow[t]{2}{*}{ Work_X_ALMP_OECD } & & & $-0.777 *$ & & & $-0.722 * * *$ & & & -0.440 \\
\hline & & & $(0.379)$ & & & $(0.207)$ & & & $(0.257)$ \\
\hline \multirow[t]{2}{*}{ Work } & & & $0.890 * *$ & & & $0.789 * * *$ & & & $0.550 *$ \\
\hline & & & $(0.399)$ & & & $(0.244)$ & & & $(0.298)$ \\
\hline Observations & 36 & 36 & 36 & 36 & 36 & 36 & 36 & 36 & 36 \\
\hline Adjusted R-squared & 0.58 & 0.60 & 0.69 & 0.63 & 0.65 & 0.76 & 0.57 & 0.59 & 0.63 \\
\hline RMSE & 4.46 & 4.36 & 3.86 & 4.22 & 4.11 & 3.40 & 4.53 & 4.40 & 4.18 \\
\hline
\end{tabular}

The Dummy for Fast Transition Countries (BG, EE, LT, LV, SI) is omitted because it is collinear with the institutional variable in this sample. 
Table 8. Modeling Employment Rates: Using OECD Labor Market-Related Expenditures (Active + Passive + Family + Housing Policies)

\begin{tabular}{|c|c|c|c|c|c|c|c|c|c|}
\hline \multirow{3}{*}{$\begin{array}{l}\text { Dependent variable: } \\
\text { EMPLOYMENT RATE }\end{array}$} & \multicolumn{3}{|c|}{ "Institution": Rigidity } & \multicolumn{3}{|c|}{ "Institution": EPL } & \multicolumn{3}{|c|}{ "Institution": PMR } \\
\hline & & & & & & & & & \\
\hline & $(1)$ & $(2)$ & $(3)$ & $(4)$ & $(5)$ & $(6)$ & $(7)$ & $(8)$ & $(9)$ \\
\hline \multirow[t]{2}{*}{ Dum_Nord } & $6.479 *$ & 2.420 & 1.554 & $5.031 * *$ & 1.834 & $4.082 * *$ & 7.021 & 2.771 & 3.816 \\
\hline & $(3.170)$ & $(3.303)$ & $(4.339)$ & $(2.053)$ & $(2.761)$ & $(1.470)$ & $(4.367)$ & $(4.635)$ & $(4.087)$ \\
\hline \multirow[t]{2}{*}{ Dum_PoRo } & $-7.733 * *$ & $-7.398 * * *$ & $-10.179 * *$ & $-11.769 * * *$ & $-10.171 * * *$ & $-12.986 * * *$ & -1.485 & -0.798 & -4.740 \\
\hline & $(3.480)$ & $(2.432)$ & $(4.823)$ & $(2.436)$ & $(2.691)$ & $(1.792)$ & $(11.744)$ & $(10.060)$ & $(9.570)$ \\
\hline \multirow[t]{2}{*}{ Dum_CTE } & -2.305 & -2.167 & -4.564 & $-4.972 * * *$ & $-3.882 *$ & $-4.434 * *$ & -1.334 & -0.435 & -2.545 \\
\hline & $(3.262)$ & $(2.315)$ & $(4.393)$ & $(1.528)$ & $(2.088)$ & $(1.554)$ & $(5.296)$ & $(4.557)$ & $(4.606)$ \\
\hline \multirow[t]{2}{*}{ Dum_MEL } & -2.650 & -3.233 & -10.995 & $-12.843 * * *$ & $-10.510 * *$ & $-18.256 * * *$ & -3.969 & -2.572 & -7.708 \\
\hline & $(5.871)$ & $(5.308)$ & $(7.198)$ & $(3.354)$ & $(3.903)$ & $(2.840)$ & $(7.211)$ & $(6.154)$ & $(5.271)$ \\
\hline \multirow[t]{2}{*}{ GDP pc.(lag) } & $0.325^{*}$ & 0.296 & 0.253 & 0.194 & 0.201 & 0.206 & 0.043 & 0.074 & 0.071 \\
\hline & $(0.176)$ & $(0.191)$ & $(0.206)$ & $(0.167)$ & $(0.187)$ & $(0.136)$ & $(0.206)$ & $(0.193)$ & $(0.204)$ \\
\hline \multirow[t]{2}{*}{ "Institution" } & $-0.163^{*}$ & -0.104 & 0.005 & $4.297 *$ & 3.503 & $6.133 * * *$ & -4.798 & -4.164 & -2.922 \\
\hline & $(0.090)$ & $(0.098)$ & $(0.122)$ & $(2.173)$ & $(2.377)$ & $(1.238)$ & $(5.224)$ & $(4.966)$ & $(4.013)$ \\
\hline \multirow[t]{2}{*}{ APFH_OECD } & -0.828 & -0.137 & $5.141 * *$ & -0.871 & -0.236 & $5.429 * * *$ & -0.363 & 0.342 & $4.860 * * *$ \\
\hline & $(0.760)$ & $(0.900)$ & $(2.331)$ & $(1.004)$ & $(1.033)$ & $(0.750)$ & $(0.725)$ & $(0.655)$ & $(1.475)$ \\
\hline \multirow[t]{2}{*}{ Religion_X_APFH_OECD } & & $-0.816 *$ & & & -0.788 & & & $-1.002 * *$ & \\
\hline & & $(0.424)$ & & & $(0.529)$ & & & $(0.455)$ & \\
\hline \multirow[t]{2}{*}{ Work_X_APFH_OECD } & & & $-0.153 * *$ & & & $-0.190 * * *$ & & & $-0.138 * * *$ \\
\hline & & & $(0.059)$ & & & $(0.021)$ & & & $(0.042)$ \\
\hline \multirow[t]{2}{*}{ Work } & & & $0.790 * *$ & & & $0.816 * * *$ & & & $0.717 * * *$ \\
\hline & & & $(0.290)$ & & & $(0.120)$ & & & $(0.206)$ \\
\hline Observations & 36 & 36 & 36 & 36 & 36 & 36 & 36 & 36 & 36 \\
\hline Adjusted R-squared & 0.60 & 0.63 & 0.71 & 0.64 & 0.67 & 0.87 & 0.57 & 0.63 & 0.70 \\
\hline RMSE & 4.36 & 4.21 & 3.74 & 4.14 & 3.97 & 2.50 & 4.50 & 4.19 & 3.79 \\
\hline
\end{tabular}

The Dummy for Fast Transition Countries (BG, EE, LT, LV, SI) is omitted because it is collinear with the institutional variable in this sample. 